\title{
Adipose stem cells and their paracrine factors are therapeutic for early retinal complications of diabetes in the $\ln s 2^{\text {Akita }}$ mouse
}

Sally L. Elshaer ${ }^{1,3}$, William Evans ${ }^{1}$, Mickey Pentecost ${ }^{4}$, Raji Lenin ${ }^{1}$, Ramesh Periasamy ${ }^{1}$, Kumar Abhiram Jha ${ }^{1}$, Shanta Alli ${ }^{1}$, Jordy Gentry ${ }^{1}$, Samuel M. Thomas ${ }^{1}$, Nicolas Sohl ${ }^{4}$ and Rajashekhar Gangaraju ${ }^{1,2^{*}}$ (D)

\begin{abstract}
Background: Early-stage diabetic retinopathy (DR) is characterized by neurovascular defects. In this study, we hypothesized that human adipose-derived stem cells (ASCs) positive for the pericyte marker CD140b, or their secreted paracrine factors, therapeutically rescue early-stage DR features in an Ins2 ${ }^{\text {Akita }}$ mouse model.
\end{abstract}

Methods: Ins $2^{\text {Akita }}$ mice at 24 weeks of age received intravitreal injections of CD140b-positive ASCs (1000 cells/1 $\mu \mathrm{L}$ ) or 20x conditioned media from cytokine-primed ASCs (ASC-CM, $1 \mu \mathrm{L}$ ). Age-matched wildtype mice that received saline served as controls. Visual function experiments and histological analyses were performed 3 weeks post intravitreal injection. Biochemical and molecular analyses assessed the ASC-CM composition and its biological effects.

Results: Three weeks post-injection, Ins $2^{\text {Akita }}$ mice that received ASCs had ameliorated decreased b-wave amplitudes and vascular leakage but failed to improve visual acuity, whereas Ins $2^{\text {Akita }}$ mice that received ASC-CM demonstrated amelioration of all aforementioned visual deficits. The ASC-CM group demonstrated partial amelioration of retinal GFAP immunoreactivity and DR-related gene expression but the ASC group did not. While Ins2 ${ }^{\text {Akita }}$ mice that received ASCs exhibited occasional (1 in 8 ) hemorrhagic retinas, mice that received ASC-CM had no adverse complications. In vitro, ASC-CM protected against TNFa-induced retinal endothelial permeability as measured by transendothelial electrical resistance. Biochemical and molecular analyses demonstrated several anti-inflammatory proteins including TSG-6 being highly expressed in cytokine-primed ASC-CM.

Conclusions: ASCs or their secreted factors mitigate retinal complications of diabetes in the Ins $2^{\text {Akita }}$ model. Further investigation is warranted to determine whether ASCs or their secreted factors are safe and effective therapeutic modalities long-term as current locally delivered therapies fail to effectively mitigate the progression of early-stage DR. Nonetheless, our study sheds new light on the therapeutic mechanisms of adult stem cells, with implications for assessing relative risks/benefits of experimental regenerative therapies for vision loss.

Keywords: NPDR, Adult stem cells, MSC, Vascular permeability, TSG-6, CD140b

\footnotetext{
*Correspondence: sgangara@uthsc.edu

'Ophthalmology, University of Tennessee Health Science Center, 930

Madison Ave, Suite\#768, Memphis, TN 38163, USA

${ }^{2}$ Anatomy and Neurobiology, University of Tennessee Health Science Center,

Memphis, TN 38163, USA

Full list of author information is available at the end of the article
}

(c) The Author(s). 2018 Open Access This article is distributed under the terms of the Creative Commons Attribution 4.0 International License (http://creativecommons.org/licenses/by/4.0/), which permits unrestricted use, distribution, and reproduction in any medium, provided you give appropriate credit to the original author(s) and the source, provide a link to the Creative Commons license, and indicate if changes were made. The Creative Commons Public Domain Dedication waiver (http://creativecommons.org/publicdomain/zero/1.0/) applies to the data made available in this article, unless otherwise stated. 


\section{Background}

Diabetic retinopathy (DR) is one of the most common causes of sight-threatening disability worldwide $[1,2]$. Patients with type 1 diabetes may show evidence of retinopathy as early as 5 years after the onset of diabetes, with most patients show varying degrees of retinopathy within 20 years. [3, 4]. Type 2 diabetic patients may experience background retinopathy (non-proliferative DR, NPDR) at the time of diagnosis, consistent with the long duration of subclinical hyperglycemia, and more than $60 \%$ of patients will experience retinopathy after 20 years of diabetes onset, with $8 \%$ developing vision-threatening complications [4, 5]. Progressive retinal vascular dysfunction in patients with DR may advance into diabetic macular edema (DME) or proliferative DR (PDR), leading to visual loss and ultimately blindness. According to the Wisconsin Epidemiologic Study of Diabetic Retinopathy, around $20 \%$ of type 1 and $14 \sim 25 \%$ of type 2 diabetic patients develop DME [6, 7].

The three predominant localized treatments for DR are laser surgery, vitrectomy surgery, and pharmacotherapy. Laser surgery, which had long been the gold standard for treatment of PDR and DME, works by targeting the late vasoproliferative stage of the disease, eliminating abnormal blood vessels that form neovascularization by intentionally destroying tissue in retinal periphery. The Early Treatment of Diabetic Retinopathy Study (ETDRS) demonstrated that focal macular photocoagulation laser surgery reduces the risk of moderate vision loss from clinically significant macular edema by half [8]. Moreover, both the Diabetic Retinopathy Study and ETDRS demonstrated that panretinal argon laser photocoagulation of the peripheral retina can halt the progression of severe NPDR or PDR by ablating ischemic retinal tissue that secretes pro-angiogenic mediators such as vascular endothelial growth factor (VEGF) [9]. Pars plana vitrectomy surgery has been used to treat recalcitrant cases of DME or macular traction secondary to PDR, but in the case of DME, visual acuity gains were not found to be significantly better than with laser $[10,11]$. Intraocular pharmacotherapy involving intravitreal injection of anti-VEGF agents and/or corticosteroids has also shown promising results in stabilizing DME and reducing retinal thickness [12-17] as well as in improving visual acuity in PDR $[18,19]$. Currently available local treatments for DR are not intended for the early stages of DR but rather for more advanced processes like DME or PDR that may have produced irreversible vision loss prior to treatment [20, 21]. Consequently, there is a pressing need for the development of disease-modifying therapeutics that can mitigate or halt the progression of NPDR by mediating inflammation and oxidative stress prior to the development of DME or PDR by targeting multiple complex pathways of the retinal neurovascular unit leading to DR [22].
Recent advances highlight the feasibility of cell-based therapies for the preservation and regeneration of the retinal neurovascular unit [23]. We have previously shown that intravitreal injection of adipose-derived stem cells (ASCs) in diabetic rats imparts neurovascular benefits [24] which were also confirmed by other independent investigators $[25,26]$. ASCs are easily obtained multipotent cells with the potential to treat a range of degenerative conditions [27, 28]. Moreover, ASCs are considered an attractive option to treat vascular destabilization and pericyte dropout seen in early DR because pericytes and ASCs are mesenchymal in origin and because a subset of ASCs share phenotypic cell surface markers with pericytes including NG2, PDGFR $\alpha$ (CD140a) and $\beta$ (CD140b), and N-Cadherin [29]. Pericyte-like ASCs may be able to preserve or even replace lost pericytes, as pericyte-like progenitors from mesenchymal stem cells (MSCs) are able to engraft at a perivascular location [30, 31]. Yet, clinical translation of ASCs may require highly purified cells with a homogenous phenotype since ASCs are naturally heterogeneous [27]. Moreover, a recent human trial using the unrefined stromal vascular fraction containing ASCs among other cell types resulted in retinal detachment and visual loss in patients with age-related macular degeneration [32, 33]. Therefore, in this study, we hypothesized that the subpopulation of CD140b-positive ASCs could therapeutically rescue early-stage clinical DR features in the Ins $2^{\text {Akita }}$ mouse.

Poor cell retention and viability in the hostile pro-inflammatory environment of the injured target tissue is a known challenge for cell-based regenerative medicine. On the other hand, paracrine factors produced by ASCs, including extracellular vesicles and proteins, have demonstrated efficacy in favorably modulating inflammatory conditions [34-37], and removal of the cells from a final therapeutic product could reduce supply chain challenges and costs typically associated with delivering cell-based products that need to be cryopreserved. A cell-free biologic may also allow for greater quality control and more precise dosing. Therefore, as an alternative to cell therapy, we also investigated the therapeutic potential of the conditioned media produced by CD140b-positive ASCs. Since both ASCs themselves would encounter an inflammatory milieu in the diabetic eye, and cytokine priming can enhance the anti-inflammatory and immunomodulatory properties of ASCs, we decided to utilize concentrated conditioned media from ASCs primed by inflammatory cytokines [38].

Using the well-established Ins $2^{\text {Akita }}$ mouse model of NPDR [39] that was successfully used in stem cell transplantation studies [40], we demonstrate that one single intravitreal injection of ASCs and/or ASC-CM therapeutically benefit the retina by modulating the 
neurovascular system, leading to improved vision. Both molecular and histological analyses further confirm the beneficial effects of the ASCs and ASC-CM in vivo. Finally, cytokine-primed ASC-CM produces differential expression of chemokines and angiogenic proteins compared to unstimulated cells with significant biological activity to rescue endothelial barrier integrity in vitro.

\section{Methods \\ Adipose-derived stem cell culture and FACS sorting of CD140b-positive cells}

Human adipose-derived stem cells used in animal studies were purchased from Lonza, Walkersville, MD (Cat\# PT-5006, Lot\#0000543947). ASCs were routinely cultured in EGM2-MV media (Lonza) and found to express MSC markers including CD105 and negative for CD31 as described previously $[29,41]$. About $2 \times 10^{6}$ ASCs were cultured in EGM2-MV media until $80 \%$ confluency reached in four to six T150 flasks (TPP Techno Plastic Products AG, Switzerland). Cells were washed with PBS and dissociated with $2 \mathrm{~mL}$ TrypLE Express (Thermo Fisher Scientific) pelleted down (300 g/5 min) and labeled for CD140b by incubation with CD140b-phycoerythrin (PE) antibody (MA1-10102, Thermo Fisher Scientific; $20 \mu \mathrm{L} / 10^{6}$ cells); isotype control IgG-PE (SA1-12186, Thermo Fisher Scientific; $20 \mu \mathrm{L} / 10^{6}$ cells) and PBS were used for unstained gating controls. Cells were incubated in the dark for 45-60 min with slow shaking on an orbital shaker at $4{ }^{\circ} \mathrm{C}$. Excess unbound antibody was removed then the cells were processed for CD140b-positive cell sorting (BD FacsAria II, BD Biosciences). The sorted cells were collected into tubes containing sterile EGM2-MV media. ASCs enriched with CD140b, as confirmed by FACS analysis, were counted by Trypan Blue exclusion method using a hemocytometer, aliquoted at $2 \times 10^{5}$ cells/ $\mathrm{ml}$ and placed in liquid nitrogen vapor cryogenic storage for further experiments.

\section{Preparation of ASC-conditioned medium (ASC-CM)}

ASC-CM was prepared from CD140b-enriched ASCs in culture. About $1 \times 10^{6}$ cells at passage 5 were cultured in T75 flasks with $10 \mathrm{ml}$ EGMV2-MV media (Lonza) at $37{ }^{\circ} \mathrm{C}, 5 \% \mathrm{CO}_{2}$. At $80 \%$ confluency (in $3-5$ days), cells were primed with cytokines for $24 \mathrm{~h}$ and TNF- $\alpha$ ( $20 \mathrm{ng} /$ $\mathrm{mL})$ and IFNY $(10 \mathrm{ng} / \mathrm{mL})$ in basal EBM2 media (Lonza). After $24 \mathrm{~h}$ of treatment, the media containing cytokines was removed, cells were washed with DPBS, and fresh serum-free EBM2 media was added. After a further $24 \mathrm{~h}$, cell-free supernatant was collected, filtered with $0.2-\mu \mathrm{m}$ syringe filter and concentrated by $20 \times$ using $3 \mathrm{KD}$ a cutoff Amicon ${ }^{\odot}$ Ultra Centrifugal Filters (Millipore Sigma). The resulting concentrated primed ASC-CM was then aliquoted and frozen at $-80{ }^{\circ} \mathrm{C}$ until further analysis.
ASC-CM prepared without cytokine stimulation was processed similarly and used for further analysis.

\section{Human cytokine antibody array}

Human cytokine antibody arrays were analyzed as previously described with slight modifications [41]. Human cytokines and angiogenic factors were assessed in the conditioned media from unstimulated or cytokine-stimulated ASCs (Lonza, Cat\# PT-5006, Lot\#0000535975; 88\% positive for CD140b) using membrane-based Human Cytokine Antibody Array C5 Kit (RayBiotech, Code: AAH-CYT-5-8) and Human Angiogenesis Array C1 (RayBiotech, Code: AAH-ANG-1-8) according to manufacturer instructions with modifications for IRDye Streptavidin detection and imaging on a LI-COR Odyssey infrared imaging system (LI-COR, Lincoln, NE, USA). These multiplexed arrays allow for the detection of multiple analytes in a sample since each printed spot corresponds to an antigen-specific antibody pair and the integrated fluorescence intensity of the spot is proportional to the relative concentration of the antigen/analyte in the sample. Duplicate membrane arrays incubated with basal media were used for background subtraction of non-specific signals. Ratiometric comparisons of individual analytes were determined from the background-subtracted integrated intensities of the spots on triplicate arrays incubated with unprimed ASC-CM or primed ASC-CM. All compared arrays were processed and imaged at once, and the integrated intensity of each spot was determined using LI-COR Odyssey software.

\section{Retinal trans-endothelial electrical resistance in vitro}

Measurements of trans-endothelial electrical resistance (TER) were performed using an electric cell-substrate impedance sensing (ECIS) device (ECIS 1600R; Applied Biophysics, Troy, NY), as described by us previously [42]. Human retinal endothelial cells (HREC; Cell Systems, Inc.) were seeded at a density of $5 \times 10^{5}$ cells $/ \mathrm{mL}$ on gold electrodes (8W10E+; Applied Biophysics, Inc.) and grown for $16 \mathrm{~h}$ until maximum resistance was attained $(\sim 1200 \Omega)$. Cells were treated with high glucose media (HG; $30 \mathrm{mM})$ and TNF- $\alpha(1 \mathrm{ng} / \mathrm{mL}$; Sino Biological Inc.) with and without the cytokine-primed and un-primed ASC-CM $(1 \mu \mathrm{L} /$ well $)$, and changes in resistance were monitored for up to $20 \mathrm{~h}$. Mannitol (30 mM) was used as an osmolality control. Resistance values for multiple wells, at $4000 \mathrm{~Hz}$, were normalized to an identical starting resistance value and averaged and presented as normalized resistance over time.

\section{Animals and intravitreal injections}

Ins2 ${ }^{\text {Akita }}$ heterozygote male mice and age-matched C57BL/6J (WT) male mice were purchased from Jackson Laboratory (Bar Harbor, ME). Mice were housed in animal facilities with $12 \mathrm{~h}$ of light-dark schedule in 
pathogen-free microisolator cages with access to food and water ad libitum. All animal experiments were performed at 24 weeks of age. Ins $2^{\text {Akita }}$ mice were subdivided into three groups based on intravitreal injection of different treatments; the first group received sterile saline injection (Akita-Saline; $1 \mu \mathrm{L} /$ eye), the second group received ASCs (Akita-ASC; 1000 cells/1 $\mu \mathrm{L} /$ eye), and the third group received cytokine-primed concentrated ASC-CM (Akita-ASC-CM; $1 \mu \mathrm{L} /$ eye) (flowchart and experimental design, Fig. 1). Age-matched WT animals that received intravitreal saline injection served as controls. Animal experiments were performed in a total of four batches with all groups and used different batches for various analyses. Retinal function was assessed in animals after 2-3 weeks post intravitreal injections followed by euthanasia to perform histological and molecular analyses except for one batch that ended day-3 post intravitreal injection for early gene expression analysis (Fig. 1). Random blood glucose measurements were obtained to confirm diabetes in Ins2 ${ }^{\text {Akita }}$ mice (Additional file 1: Figure S1).

\section{Flash electroretinography (ERG)}

To assess retinal function, dark-adapted flash ERG (Diagnosys Espion E2 ERG system, Diagnosys LLC, Lowell, MA) scotopic intensity response series was performed in anesthetized mice before and after intravitreal injections. ERG was performed on each mouse sequentially beginning with the lowest excitation with gradually increasing intensity $(0.0025,0.025,0.25,2.5$, and 25 cd.s. $\mathrm{m}^{2}$ ). Each light intensity was repeated four to five times, with an inter-stimulus interval ranging from $20 \mathrm{~s}$ for $\operatorname{dim}$ flashes to $1 \mathrm{~min}$ for the brightest flashes. Three to five ERG traces at each flash luminance were averaged, and the amplitude of the a-wave was measured from the pre-stimulus baseline to the a-wave trough while b-wave was measured from a-wave trough to the peak of the first visible b-wave.

\section{Optokinetic measurements}

Awake mice were placed on a platform inside the OptoMotry virtual reality optokinetic reflex nystagmus (OKN) system to quantify the visual acuity and contrast sensitivity thresholds (OptoMotry, CerebralMechanics, Lethbridge, Alberta, Canada) as described previously [43]. According to published methodologies [44], a step-wise paradigm defined by OptoMotry software was used with the screens of contrasting bars of light not visible to the investigator and the investigator was blinded to the groups. Acuity testing was performed at $100 \%$ contrast with varying spatial frequency threshold (i.e., white versus black stripes), while contrast sensitivity testing was performed at a fixed spatial frequency threshold $(0.042 \mathrm{c} / \mathrm{d})$.

\section{Fluorescein angiography and retinal fundus imaging}

Fluorescein angiography (FA) was performed as described previously [45] with slight modifications in anesthetized mice from all study groups. Micron IV retinal imaging microscope (Phoenix Research Labs, Pleasanton, CA) lens was appended to the cornea, and video imaging was performed after intraperitoneal injection of $75 \mu \mathrm{L}$ of $1 \%$ sodium fluorescein (AK-Fluor ${ }^{\circ}$, Akorn Animal Health, Lake Forest, IL). Images were captured between 1 and $4 \mathrm{~min}$ in the left eye in both brightfield and green fluorescence filter settings.

\section{Optical coherence tomography (OCT)}

OCT was performed as described previously by our group [46] with slight modifications in anesthetized mice

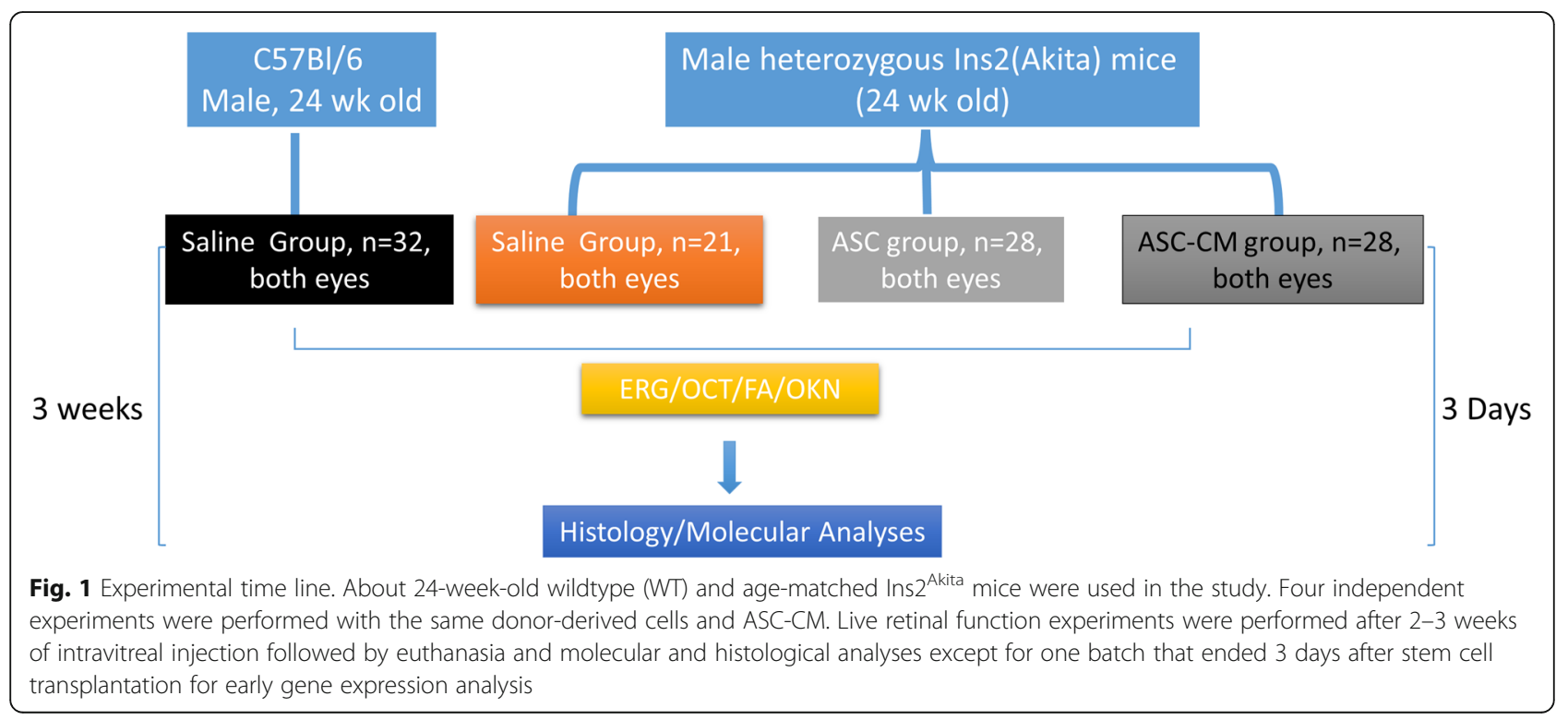


from all study groups. Animals were placed on a platform attached to a modified microscope stage that allowed movement in the $X, Y$, and $Z$ planes as well as rotation around the animal's rostral-caudal axis. OCT was completed using the Micron IV Image-Guided OCT system for rodents (Phoenix Research Labs). OCT image gathering was performed with Reveal Micron OCT software, and retinal thickness was measured in a blinded fashion around the optic disk (1620 $\mu$ m length) using the Insight segmentation software (Phoenix Research Labs) by manually creating layers that cover the ganglion cell layer (GCL) to outer nuclear layer (ONL).

\section{Vascular permeability}

Vascular permeability in mice was assessed by the albumin extravasation assay method as described by others and us previously with slight modifications [24, 47-49]. Briefly, at the end of the study, mice were anesthetized with isoflurane and received tail vein injection of FITC-BSA (100 mg/ $\mathrm{kg}$, Sigma-Aldrich). About $1 \mathrm{~h}$ after injection, mice were euthanized, and eyes were enucleated and immersed in $4 \%$ paraformaldehyde for $1 \mathrm{~h}$. After fixation, retinas were dissected and flat-mounted and images were captured at high resolution using $20 \times$ objective with Biotek Lionheart FX Automated Microscope (Bio Tek Instruments Inc., Winooski, VT) under GFP imaging filter cube for FITC-BSA. The total fluorescence intensity was quantified using ImageJ software (NIH.gov). The fluorescence values were then normalized to the plasma level of FITC determined by fluorimeter (Molecular Devices, Sunnyvale, CA).

\section{GFAP immunohistochemistry}

Eyes were enucleated at 3 weeks post-ASCs or ASC-CM injections and fixed in 4\% paraformaldehyde in PBS. GFAP immunohistochemical analysis was performed by an investigator blinded to the study groups. Briefly, 8 - $\mu \mathrm{m}$ paraffin-embedded retinal sections from near the optic nerve head $(\mathrm{ONH})$ were deparaffinized and incubated overnight with GFAP primary antibodies (Thermo Fisher Scientific, 1:250) at $4{ }^{\circ} \mathrm{C}$ in a humidified chamber. Next day, sections were washed three times with $1 \times$ PBS and incubated with a 1:500 goat anti-mouse IgG conjugated to AlexaFluor488, and DAPI (both Thermo Fisher Scientific) to stain nuclei for $1.5 \mathrm{~h}$ at room temperature, then washed with $1 \times$ PBS. For each slide, one section was kept as a negative control without primary antibody. Digital images were captured from regions intermediate to the $\mathrm{ONH}$ and the ora serrata from three retinal sections approximately $20-100 \mu \mathrm{m}$ apart using a Zeiss 710 laser scanning confocal microscope (Carl Zeiss Promenade, Germany) and quantification of pixel intensities of antigen was computed using ImageJ analysis software.

\section{Histological evaluation}

Eyes were enucleated at 3 weeks post-ASCs or ASC-CM injections and fixed in $4 \%$ paraformaldehyde in PBS, $\mathrm{pH}$ 7.4. To evaluate histological changes, $8 \mathrm{~mm}$ paraffin embedded retinal sections from near the optic nerve head $(\mathrm{ONH})$ were deparaffinized and stained with hematoxylin and eosin. Sections were mounted in Permount mounting medium and digital images were captured using a 20X objective on a Nikon Optiphot 2 upright brightfield microscope.

\section{Immunohistochemistry (IHC)}

IHC was performed to localize the human ASCs in the retina. Post euthanasia eyes from all groups were enucleated, lens and vitreous were removed by cutting through cornea. Retinal eyecups were fixed in $4 \%$ paraformaldehyde in $0.1 \mathrm{M}$ phosphate buffer $(\mathrm{PB})$ for $4 \mathrm{~h}$ at $4^{\circ} \mathrm{C}$. Following this, eyecups were cryopreserved in 15-30\% sucrose in $0.1 \mathrm{M} \mathrm{PB}$, embedded in OCT in a cryostat (Microm-HM 550, Thermo scientific) at $-20^{\circ} \mathrm{C}$, sectioned at $12 \mu \mathrm{m}$ thickness along a dorsal to the ventral axis. Sections were placed on to L-poly lysine coated slides washed three times with $0.1 \mathrm{M}$ phosphate buffer saline (PBS) and $0.01 \%$ Triton-X and immersed in 5\% normal serum in 0.1M PBS for $1 \mathrm{~h}$ to block non-specific binding sites. Retinal sections were then incubated in the primary antibody against human histone (dilutions: $2 \mu \mathrm{g} /$ $\mathrm{ml}$, rabbit polyclonal, catalog number: ZO334, Dako) for $48 \mathrm{~h}$ at $4^{\circ} \mathrm{C}$. After three consecutive washes with $0.1 \mathrm{M}$ PBSTriton- $X$, sections were incubated in secondary antibodies (goat anti-rabbit IgG Alexa Fluor 546, dilution: $2 \mu \mathrm{g} / \mathrm{ml}$, Thermo Fisher Scientific) for $4 \mathrm{~h}$ at room temperature. Sections were then washed, incubated with DAPI for nuclear staining and mounted (Lab VisionTM PermaFlourTM, Fisher scientific). Retinal sections were examined under a Zeiss LSM 710 laser scanning confocal microscope with a $20 \mathrm{X}$ objective with suitable filters. Tissue sections without exposure to the primary antibody were used as negative controls for immunostaining. Human ASCs cultured in a 24-well plate on coverslips served as positive controls.

\section{Gene expression analysis}

Eyes were enucleated at 3 days or 3 weeks post-ASCs or ASC-CM injections, and retinal tissues were snap frozen. Whole mouse retinal tissue was used to isolate RNA using NucleoSpin ${ }^{\circ}$ RNA Plus kit (Macherey-Nagel Inc., Bethlehem, PA), following the manufacturer's protocol. Subsequently, about $250 \mathrm{ng}$ of total RNA from each tissue was converted to cDNA using SuperScript III first-strand synthesis supermix (Thermo Fisher Scientific). The resulting cDNA sample served as a template for real-time qPCR using TaqMan probes (Table 1) and accompanying Master Mix (Applied Biosystems, Foster 
Table 1 TaqMan assay primer and probes for gene transcript analysis

\begin{tabular}{llll}
\hline Genes & Assay ID & Reference sequence & Amplicon length \\
\hline 18S ribosomal RNA (18s) & Mm04277571 & NR_003278 & 115 \\
$\begin{array}{l}\text { Serine (or cysteine) peptidase inhibitor, } \\
\text { member 1 (Serping1) }\end{array}$ & Mm00437835 & NM_009776.3 & 103 \\
Chemokine (C-C motif) ligand 2 (CCL2) & Mm00441242 & NM_011333.3 & 74 \\
Laminin, alpha 5 (LAMA5) & Mm01222029 & NM_001081171.2 & 64 \\
Endothelin 2 (EDN2) & Mm00432983 & NM_007902.2 & 74 \\
Guanylate binding protein 2 (GBP2) & Mm00494576 & 77 \\
Lectin, galactose binding, soluble 9 (LGALS9) & Mm00495295 & 68 \\
Tissue inhibitor of metalloproteinase 1 (TIMP1) & Mm01341361 & 100 \\
Cholesterol 25-hydroxylase (CH25H) & Nm00515486 & NM_001159301.1 & 126 \\
Intercellular adhesion molecule 1 (ICAM-1) & Mm0117587684.1 & NM_009890.1 \\
Crystallin, beta B2 (CRYBB2) & Mm02343649 & NM_010493.2 & 129 \\
Cysteine and glycine-rich protein 3 (Csrp3) & Mm00443379 & 60 \\
\hline
\end{tabular}

City, CA). PCR amplification was carried out using Quantstudio3 (Applied Biosystems). The expression levels of gene transcripts were determined using $2^{-\mathrm{DDCt}}$ and normalized to $18 \mathrm{~s}$ rRNA as described by us previously [50]. All mouse probes used in the study were verified not to display off-target effects with human gene transcripts.

\section{Statistical analysis}

The data shown here is represented as a mean \pm standard error of the mean (SEM). Statistical significance was calculated using unpaired Student's $t$ test or one-way ANOVA followed by Bonferroni correction for multiple comparisons to detect significant interactions among various groups. Significance for all tests was determined at $\alpha=0.05$, GraphPad Prism, Ver.6.

\section{Results}

Paracrine activity of ASCs can support endothelial barrier integrity in vitro

Ins $2^{\text {Akita }}$ mice are a non-obese model for diabetic complications. These mice develop hyperglycemia and hypoinsulinemia by 4 weeks of age [39]. Studies have shown moderate pathological defects in the retinal neurovascular unit of Ins $2^{\text {Akita }}$ mice, including pericyte loss, microglial reactivity, and vascular leakiness, resembling early-stage DR [39]. The overarching goals of this study are to determine whether the retinal pathologies observed in the Ins $2^{\text {Akita }}$ mouse (i) result in functional visual deficits and whether (ii) ASCs and/or their paracrine secretions could act therapeutically to preserve visual function (Fig. 1). To ensure relative homogeneity of the cell source and to select for ASCs that share cell surface markers with pericytes, we sorted out CD140-positive ASCs (Additional file 2: Figure S2). We used those cells and their paracrine factors in all functional experiments.
Mesenchymal stem cells are well known to respond to environmental stimuli with changes in the composition of secreted proteins. It has been shown that MSCs take on an anti-inflammatory phenotype when primed with inflammatory cytokines [38]. Considering that ASCs would encounter an inflammatory milieu in vivo, we wondered if priming the cells with cytokines prior to collecting the paracrine factors in the conditioned media could enhance any apparent therapeutic activity. Using membrane-based antibody arrays for the multiplexed semi-quantitative profiling of analytes and immunoblot analyses of additional analytes, we confirmed that cytokine priming of ASCs changes the composition of the secretome by upregulating the secretion of anti-inflammatory proteins like TNF-stimulated gene 6 protein (TSG-6), immune modulatory proteins like indoleamine 2,3-dioxygenase (IDO), antioxidant proteins like superoxide dismutase 2 (SOD2), and various cytokines, chemokines, and factors that are known to modulate immunity, angiogenesis, and neuroprotection including IL-6, IL-8, CCL2, CXCL9, CCL5, CXCL10, CXCL11, CCL7, and ANG-1 with no apparent effect on cell viability (Fig. 2a, b, Additional file 3: Figure S3). These results suggest that the conditioned media from unprimed and primed cells would have different biological effects.

We next tested the ability of unprimed or primed ASC-CM to preserve retinal barrier function in an in vitro model of the retinal endothelial barrier by measuring trans-endothelial electrical resistance (TER) (Fig. 2c, d). TNF $\alpha$ and glucose play major roles in the breakdown of the blood-retinal barrier in DR [51-53]. Human retinal endothelial cells (HREC) exposed to high glucose (HG), and TNF- $\alpha$ induced a sustained reduction in barrier integrity as evidenced by decreased TER at $20 \mathrm{~h}$ time point (TNF + HG, $0.4 \pm 0.01$; control, $1.0 \pm 0.0, p<0.001$ Fig. $2 \mathrm{~d}$ ). On the other hand, these effects were partially rescued by 

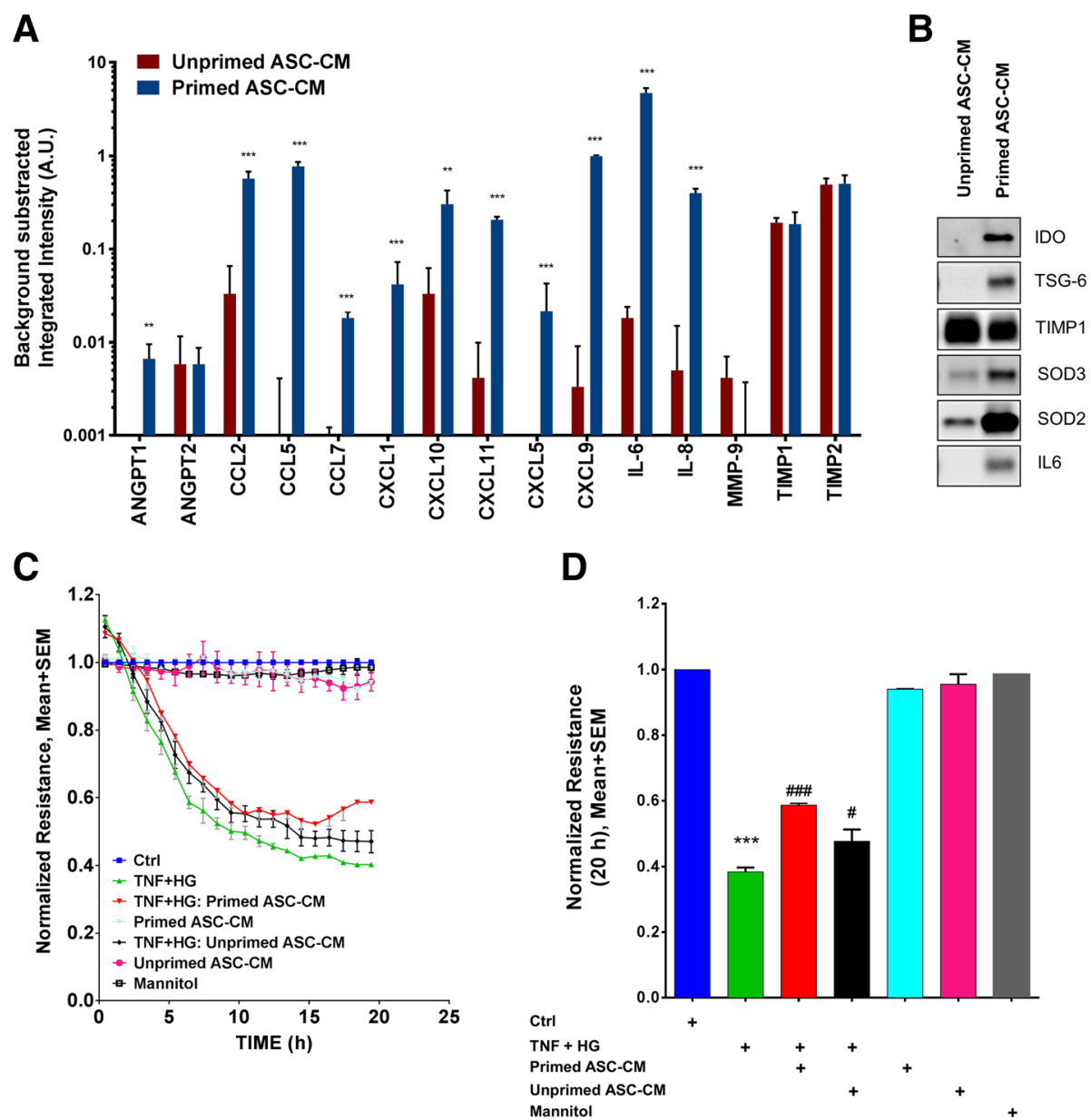

Fig. 2 Cytokine priming enhances chemokine and angiogenic proteins in ASC-CM and rescues trans-endothelial resistance in vitro. a Assessment of relative protein expression using membrane antibody arrays to determine differential expression of chemokines and angiogenic proteins in unprimed and cytokine-primed ASC-CM. Data represent mean \pm SD from one donor ASC performed in triplicates. ${ }^{*} p<0.05 ;{ }^{* *} p<0.01 ;{ }^{* * *} p<0.001$ compared to unprimed ASC-CM. $\mathbf{b}$ Increased levels of IDO, TSG-6, SOD3, SOD2, and IL6 but not TIMP1 proteins in cytokine-primed ASC-CM as assessed by immunoblot. c Representative ECIS tracings plotted as normalized resistance expressed as mean \pm SEM from TNF + HG with various study groups. $\mathbf{d}$ Quantification of normalized resistance plotted as a reference to untreated control cells at $20 \mathrm{~h}$. Data represented from two independent experiments performed in duplicates. ${ }^{* * *} p<0.001$ compared to Ctrl; \#, $p<0.05$, \#\#\#, $p<0.001$ compared to TNF + HG-treated cultures

treatment with either primed or un-primed ASC-CM, primed $\mathrm{CM}(0.59 \pm 0.006, p<0.001)$, and unprimed $\mathrm{CM}$ $(0.48 \pm 0.036, p<0.05)$ as compared to TNF + HG-treated cultures. Mannitol, used as an osmolality control, did not influence the TER measurements (Fig. 2c). These results indicate that ASCs can preserve endothelial barrier integrity via paracrine signaling. Since primed $\mathrm{CM}$ was superior to unprimed CM by $23.2 \%(p<0.05)$ (Fig. $2 \mathrm{~d}$ ), we decided to use this conditioned media in addition to injection of ASCs in subsequent animal experiments, described below and diagrammed in Fig. 1.

\section{Intravitreal injection of ASCs and ASC-CM mitigates vascular permeability in Ins2 $2^{\text {Akita }}$ mice}

Retinal vascular permeability has been reported in Ins $2^{\mathrm{A}-}$ ${ }^{\text {kita }}$ mice [39]. We did not observe profound differences between Ins $2^{\text {Akita }}$ and WT mice by fluorescein angiography (Additional file 4: Figure S4), which was also reported by Ambati group [40]. To better analyze retinal vascular permeability, we performed tail vein injection of FITC-BSA and then prepared fixed retinal flat mounts for quantitative microscopy analyses. As shown in Fig. 3, Ins $2^{\text {Akita }}$ mice experienced enhanced vascular leakage of FITC-BSA in retinal vascular beds as illustrated in representative retinal flat mounts (Fig. 3a). As shown in Fig. 3b, FITC-BSA fluorescence in retinal flat mounts normalized to total plasma fluorescence in respective animals suggested significant increase in vascular leakiness in Ins $2^{\text {Akita }}$ mice that received saline injection compared to WT animals (Akita-saline, $1.9 \times 10^{7} \pm 1.13 \times 10^{6}$; WT, $1.5 \times 10^{7} \pm 1.7 \times 10^{6}$, integrated density/unit retinal area $\left.\left(\mu \mathrm{m}^{2}\right), p<0.05\right)$. Interestingly, intravitreal injection of 


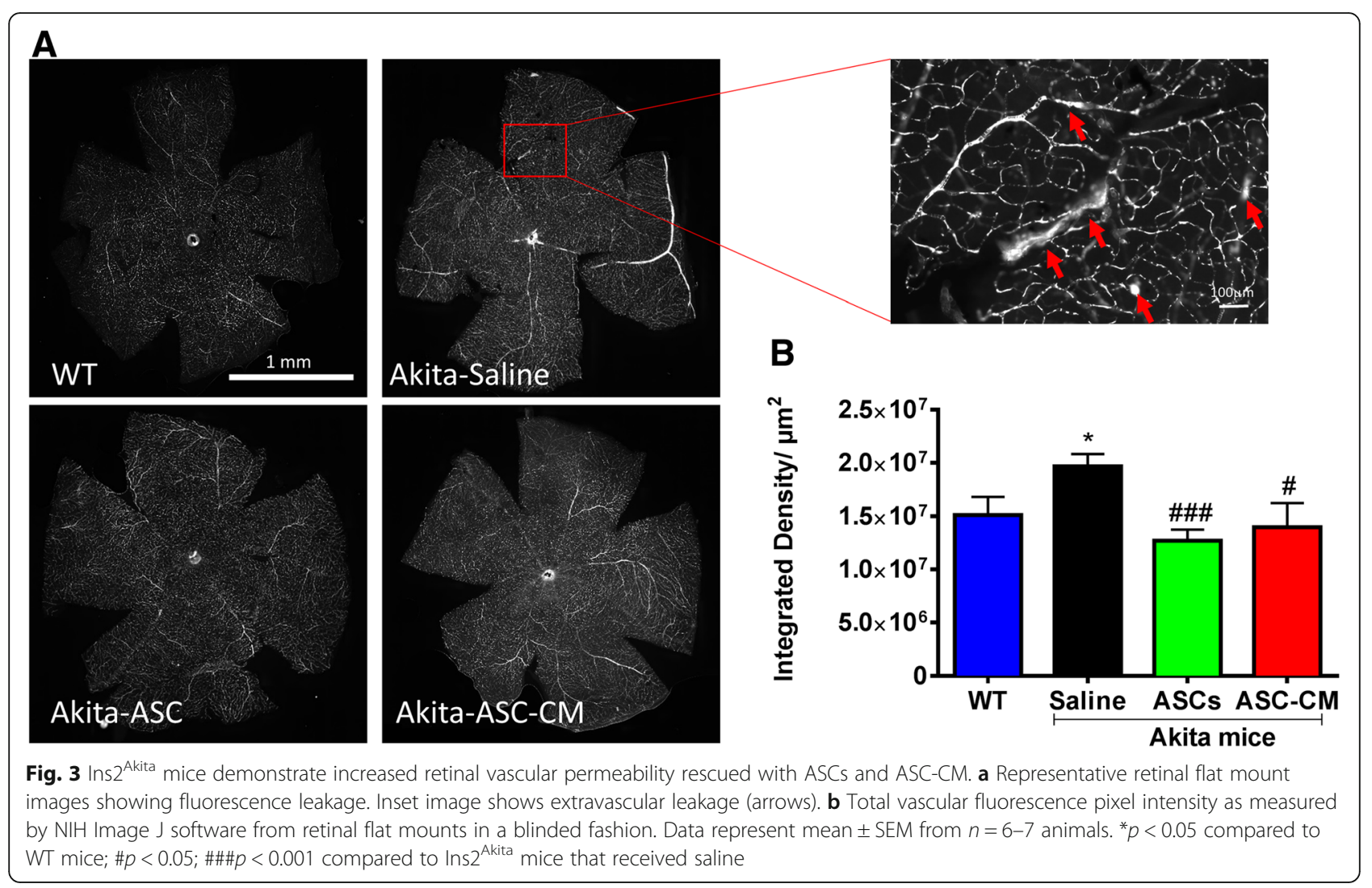

ASCs or ASC-CM protected retinal vascular beds and significantly attenuated vascular leakage of FITC-BSA when compared to Ins $2^{\text {Akita }}$ mice that received saline (Akita-ASC, $1.27 \times 10^{7} \pm 1.03 \times 10^{6}$ integrated density/ $\mu \mathrm{m}^{2}$; Akita-ASC-CM, $1.4 \times 10^{7} \pm 2.3 \times 10^{6}$, integrated density $/ \mu \mathrm{m}^{2}, p<0.05$, Fig. $\left.3 \mathrm{~b}\right)$. The preservation of vascular function by ASCs or their paracrine factors in the Ins $2^{\text {Akita }}$ indicates that these treatments might also mitigate any defects in visual function in this model.

\section{Intravitreal injection of ASC and ASC-CM improve retinal} function and vision in Ins $2^{\text {Akita }}$ mice

Ins $2^{\text {Akita }}$ mice and age-matched WT mice were tested for their visual function 2-3 weeks after ASC or ASC-CM injections using ERG (see Fig. 1 for process map). ERG is one of the most widely used measures of functional performance/deficits in the visual pathway in diabetic rodents [24, 40]. ERG data generated from studies across three batches of animals are presented. We first assessed changes in b-wave amplitudes over increasing flashlight intensities starting from 0.0025 to 25 cd.s.m ${ }^{2}$ (Fig. 4a). Increasing amplitudes with increasing flash intensities could be discerned with the most robust changes detected at 25 cd.s.m ${ }^{2}$. The b-wave amplitude at 25 cd.s.m ${ }^{2}$ flash light intensity in WT animals were $323.8 \pm 36.24 \mu \mathrm{V}$ which significantly decreased to $213.8 \pm 27.8 \mu \mathrm{V}$ in Akita mice that received saline $(p<0.05$, Fig. $4 \mathrm{~b})$. In line with our results, b-wave and oscillatory potentials in scotopic ERG were severely impaired in 6-9-month-old Ins $2^{\text {Akita }}$ mice $[40,54]$. On the other hand, intravitreal injection of ASCs or their concentrated conditioned medium resulted in improvement in b-wave amplitude at 25 cd.s.m ${ }^{2}$; $252.4 \pm 23.24 \mu \mathrm{V}$ for Akita-ASC group and 247.3 \pm $24.21 \mu \mathrm{V}$ for Akita-ASC-CM group (Fig. 4b), though the data did not reach statistical significance $(P>0.05)$. Considering the lack of effectiveness, we computed the values from Fig. $4 \mathrm{~b}$ as normalized to their respective pre-injection baseline b-wave amplitudes. This normalization was conducted via a calculation of the ratio of the post-injection b-wave amplitude to the pre-injection b-wave amplitude, which accounted for individual animal variations over the duration of the experiment. As expected, Akita mice that received saline had lower b-wave amplitudes as compared with WT group (Akita-Ctrl, $0.98 \pm 0.1$; WT $1.35 \pm 0.1, p<0.05$ ). Interestingly though, both ASC and ASC-CM group now demonstrated a significant improvement in the normalized b-wave amplitude when compared with Akita mice that received a saline injection (Akita-ASC, $1.9 \pm 0.4, \mathrm{p}<0.05$; Akita-ASC-CM, $1.5 \pm 0.2, p<0.05$ ). (Fig. 4c).

While b-wave amplitude represents Muller cell response, a-wave defects represent mostly photoreceptor 


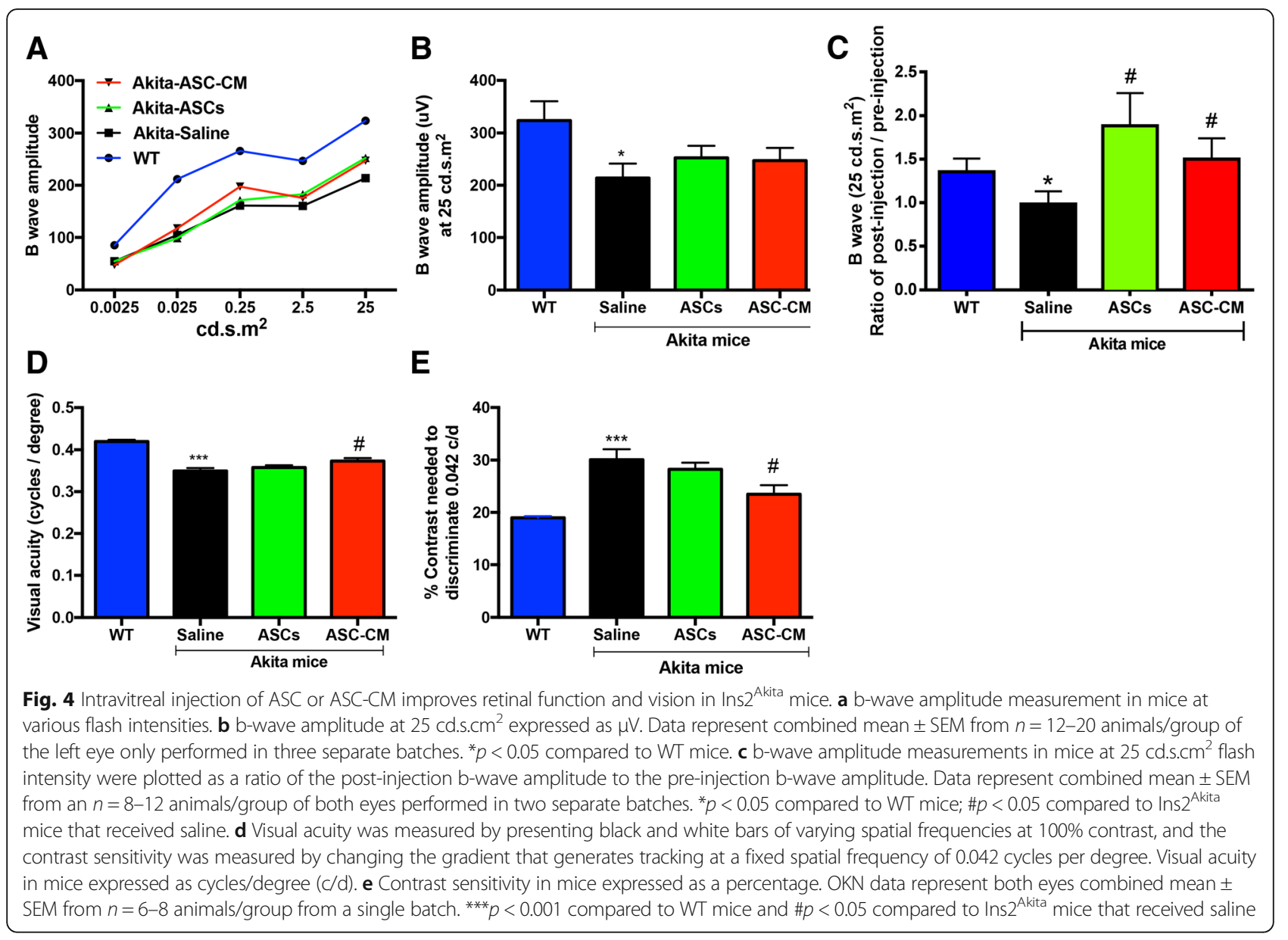

cells. Similar to b-wave, a-wave amplitudes were recorded at increasing light intensities starting from 0.0025 to 25 cd.s.m ${ }^{2}$ (Additional file 5: Figure S5A), where most robust changes were also observed at 25 cd.s.m ${ }^{2}$. While the mean amplitudes in WT mice group were $-183.8 \pm$ $19.45 \mu \mathrm{V}$, it significantly decreased in Akita mice group $(-125.5 \pm 17.33 \mu \mathrm{V}, p<0.05$, Additional file 5: Figure S5B). In contrast to b-wave amplitudes, injection of ASCs or ASC-CM failed to improve a-wave with values remained significantly lower than those of WT mice (Akita-ASC: $-144.7 \pm 10.71 \mu \mathrm{V}$, $p>0.05$ and Akita-ASC-CM: $-142.0 \pm 10.94 \mu \mathrm{V}, p>$ 0.05, Additional file 5: Figure S5B).

Visual dysfunction in Ins $2^{\text {Akita }}$ mice has been shown to manifest as a change in visual acuity and contrast sensitivity defects through visual tracking behavior [40]. In this study, we measured visual acuity and contrast sensitivity 2-3 weeks post intravitreal injection of ASCs or ASC-CM. Studies described here were performed in one batch of animals. As expected, Ins $2^{\text {Akita }}$ mice demonstrated a significant reduction in visual acuity as compared to WT mice (WT-ctrl, $0.42 \pm 0.004 \mathrm{c} / \mathrm{d}$; Akita-Saline, $0.35 \pm 0.007 \mathrm{c} / \mathrm{d}$, $p<0.001$, Fig. $4 \mathrm{~d})$. Interestingly, while Ins $2^{\text {Akita }}$ mice that received ASC injection failed to improve visual acuity $(0.36 \pm 0.005, p=0.17), \quad$ Ins $2^{\text {Akita }}$ mice that received ASC-CM demonstrated a significant alleviation in visual acuity as compared to Ins $2^{\text {Akita }}$ mice that received saline (Akita-ASC-CM, $0.37 \pm 0.007, p<0.05$ ). Any decrease in visual acuity may likely result in an increase in contrast sensitivity, and as expected, Ins $2^{\text {Akita }}$ mice demonstrated a significant increase in contrast needed to discriminate a fixed $0.042 \mathrm{c} / \mathrm{d}$ of acuity (WT-Ctrl, 19 $\pm 0.3 \%$; Akita-Saline, $30.1 \pm 1.98 \%, p<0.001$, Fig. 4 e). In a similar fashion to visual acuity, only Ins $2^{\text {Akita }}$ mice that received ASC-CM demonstrated a significant improvement in contrast sensitivity as compared to Akita mice that received a saline injection $(23.48 \pm 1.73 \%, p<$ 0.05). Although Ins $2^{\text {Akita }}$ group that received ASC injection also showed a decrease, the data did not reach statistical significance $(28.23 \pm 1.28 \%, p=0.226)$.

\section{Intravitreal injection of ASCs and ASC-CM do not adversely affect retinal architecture}

We used OCT to assess the retinal architecture. As shown in Fig. 5, WT mice showed normal appearance of retinal architecture (Fig. 5a). In line with published 


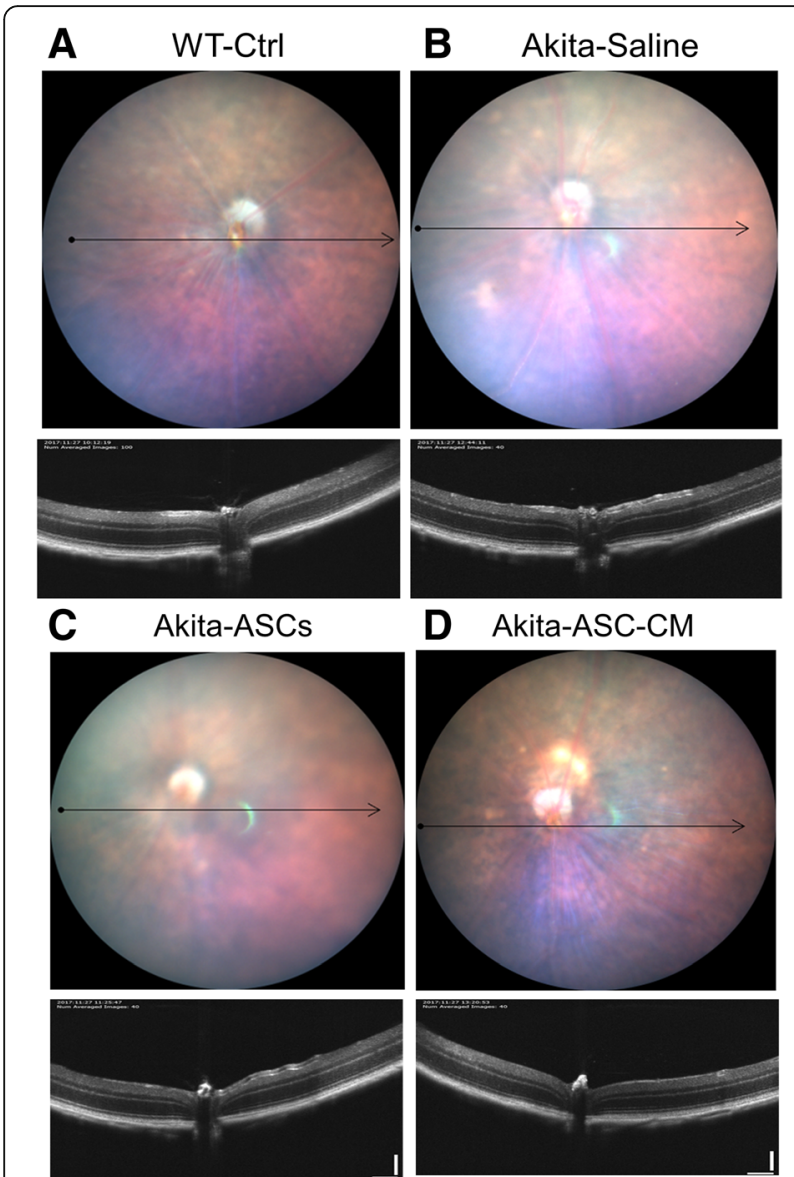

E

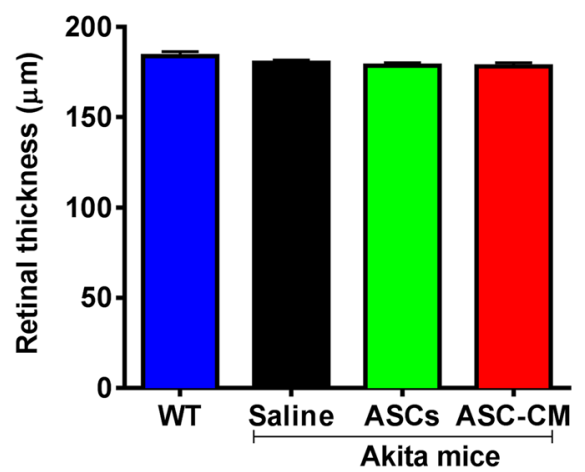

Fig. 5 Ins $2^{\text {Akita }}$ mice demonstrate no apparent changes in OCT with and without ASCs and ASC-CM. Representative brightfield images showing b-scan location (arrow) with occasional bright spots (upper panels) in WT (a) and Ins2 ${ }^{\text {Akita }}$ mice with saline (b), ASCs (c), and ASC-CM (d) with their vitreous, retinal layers, and choroidal layers clearly visible (lower panels). e Central retinal thickness in the study groups. Data are representative from $n=3($ WT); 4-7 animals (other groups) both eyes included

literature [55], Ins $2^{\text {Akita }}$ mice that received saline did not show any significant change in retinal architecture or retinal thickness around optic nerve head as detected by OCT (Fig. 5b, e). This near normal appearance of the retina was confirmed by $\mathrm{H} \& \mathrm{E}$ staining in some representative animals (Additional file 6: Figure S6A).
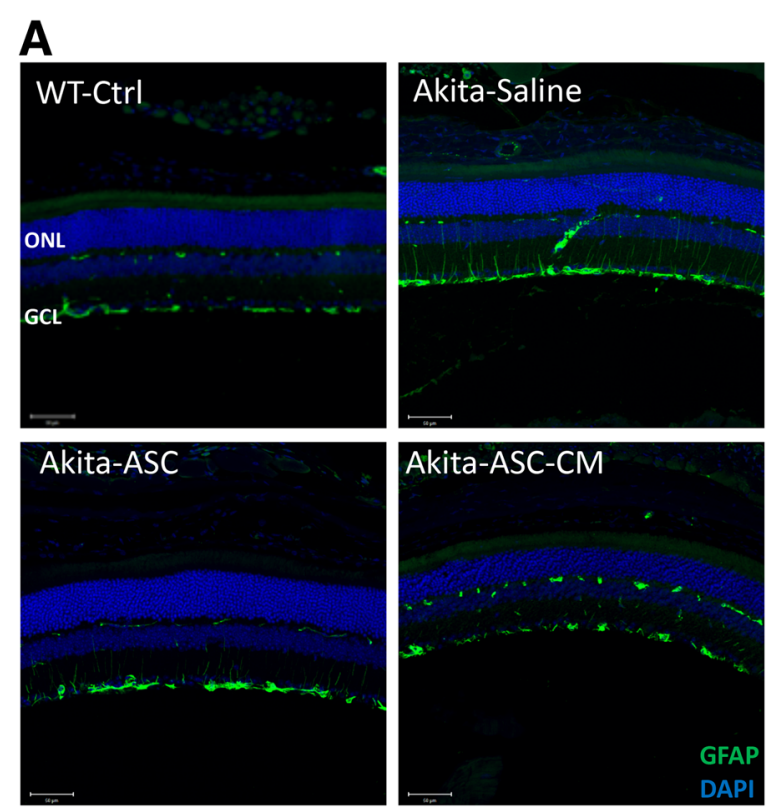

\section{B}

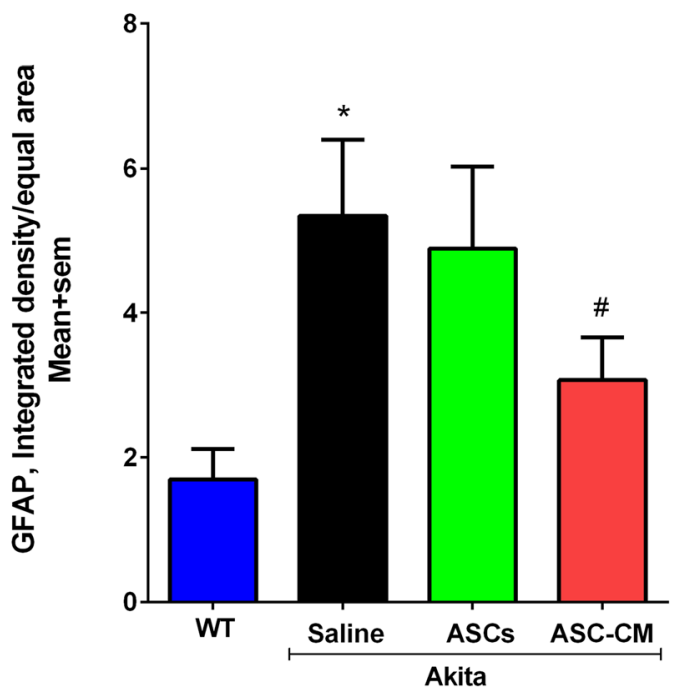

Fig. 6 Ins $2^{\text {Akita }}$ mice show increased GFAP immunoreactivity partially rescued with ASC-CM. a Representative confocal images showing the GFAP immunostaining (green) counterstained with DAPI (blue) in wildtype animal (WT-Ctrl), Ins2 ${ }^{\text {Akita }}$ mice that received saline (Akita-Saline), Ins2 ${ }^{\text {Akita }}$ mice that received ASCs (Akita-ASC), and Ins $2^{\text {Akita }}$ mice that received ASC-CM (Akita-ASC-CM). b Quantification of GFAP intensity expressed as average mean integrated intensity measured by $\mathrm{NIH}$ ImageJ. Data represent combined mean \pm SEM from $n=4-7$ eyes/group performed in one batch. ${ }^{*} p<0.02$ compared to WT mice and \# $p=0.06$ compared to $\operatorname{lns} 2^{\text {Akita }}$ mice that received saline. Scale $=50 \mu \mathrm{m}$

ASCs could occasionally be visualized in OCT in the vitreous on top of the retina (Additional file 6: Figure S6A-B). Interestingly, Ins2 ${ }^{\text {Akita }}$ mice that received ASC or ASC-CM did not result in any further deterioration or change in retinal thickness around the optic nerve head (Fig. 5c-e) except for one mouse out of eight that received ASCs demonstrated 


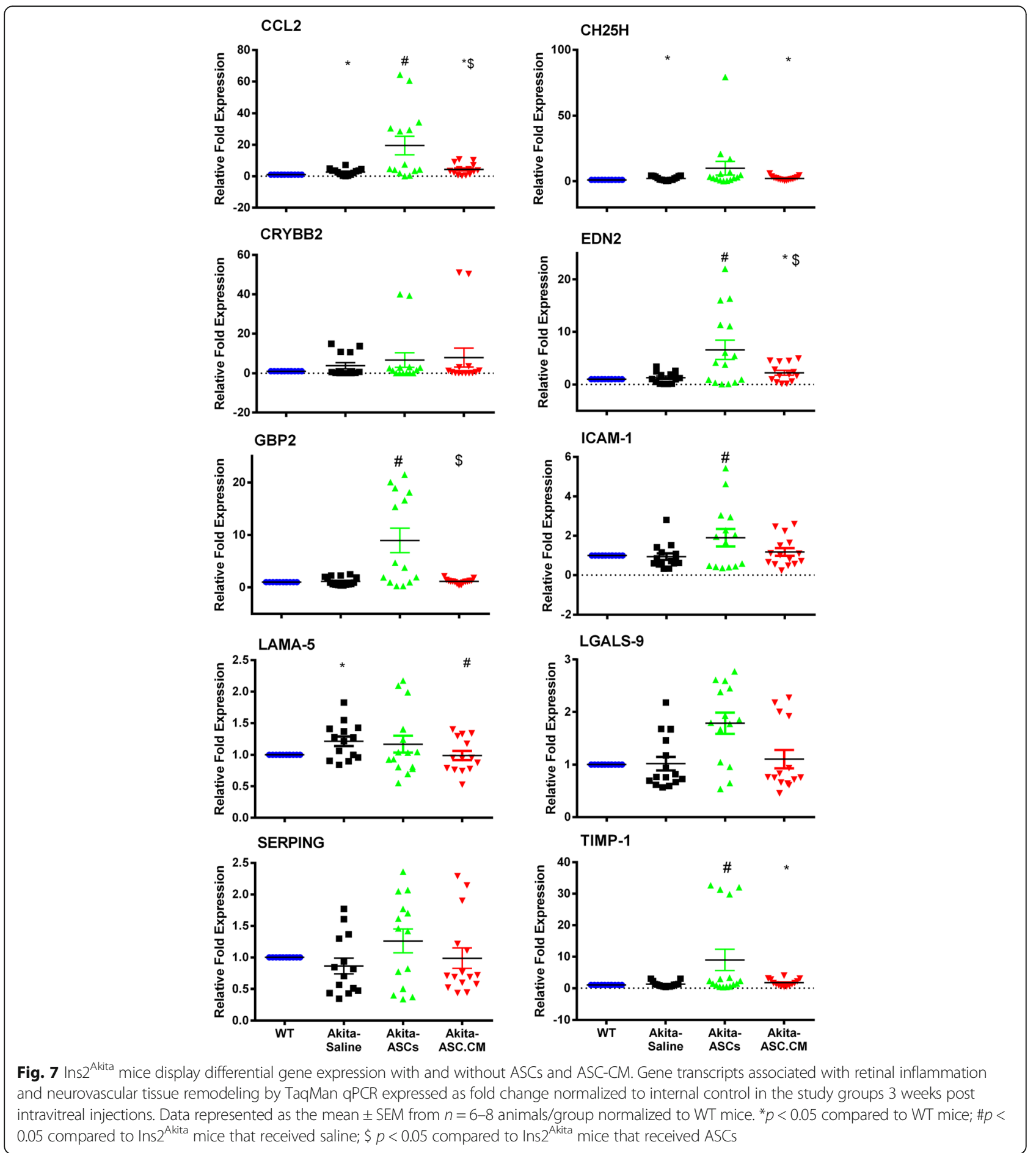

retinal tugging and hemorrhage (Fig. $5 \mathrm{c}$ and Additional file 4: Figure S4, Additional file 6: Figure S6B). H\&E staining for Ins $2^{\text {Akita }}$ mice that received ASCs or ASC-CM did not reveal any retinal defects seen in vivo perhaps suggesting transient nature of the observed retinal defects in this model or rare occurrence (Additional file 6: Figure S6A).
Intravitreal injection of ASC-CM but not ASCs marginally attenuates enhanced retinal expression of GFAP in Ins $2^{\text {Akita }}$ mice

Upregulation of GFAP expression in Müller glial cells is a hallmark of neuroinflammation and reactive gliosis [56]. In our studies, while GFAP immunoreactivity was restricted to GCL in WT mice, in Ins2 ${ }^{\text {Akita }}$ mice that 
received saline, GFAP immunoreactivity increased in GCL with thicker processes observed reaching to the outer retina (WT-Ctrl: $1.7 \pm 0.4$; Akita-Saline: $5.3 \pm 1.0$ integrated density/equal area; $p<0.02$ Fig. $6 \mathrm{a}, \mathrm{b})$. Ins2 ${ }^{\mathrm{A}-}$ kita mice that received ASCs failed to show any significant reduction in GFAP expression (Akita-ASCs: $4.9 \pm$ 1.1; Akita-Saline: $5.3 \pm 1.0$ integrated density/equal area; $p<0.01$, Fig. 6a, b). However, Ins $2^{\text {Akita }}$ mice that received ASC-CM demonstrated an overall reduction in GFAP immunoreactivity, yet, the data are only borderline significant when an outlier is excluded from the data (Akita-ASC-CM: $3.0 \pm 0.5$; Akita-Saline: $5.3 \pm 1.0$ integrated density/equal area; $p=0.06$, Fig. $6 \mathrm{~b}$ ).

\section{ASCs and ASC-CM modulate retinal gene expression in Ins $2^{\text {Akita }}$ mice}

As shown in Fig. 7, Ins2 ${ }^{\text {Akita }}$ mice experienced the altered expression of genes associated with retinal inflammation and neurovascular tissue remodeling in response to diabetes-related stressors [57]. Compared to age-matched WT mice, Ins $2^{\text {Akita }}$ mice that received saline showed increased gene transcripts of $\mathrm{Ccl} 2$, Ch25h, and Lama5 in the retinal lysates at 3 weeks post-injection ( $\mathrm{Ccl} 2: 2.7 \pm 0.5$, Ch25h: $2.3 \pm 0.4$, Lama5: $1.2 \pm 0.1$, as compared to WT mice: $1 \pm 0.0, p<0.05)$. Interestingly, Ins $2^{\mathrm{Akita}}$ mice that received intravitreal injections of ASCs showed a higher expression profile of genes at 3 weeks including $\mathrm{Ccl} 2$, Edn2, Gbp2, Icam-1, and Timp1, where expression of these genes were significantly higher as compared to the Akita-Saline group (Ccl2: $19.6 \pm 5.9$ as compared to Akita-Saline, Edn2: $6.6 \pm 1.8$ as compared to $1.3 \pm 0.3$ for Akita-Saline, Gbp2: $8.9 \pm 2.3$ as compared to $1.2 \pm 0.2$ for Akita-Saline, Icam-1: $1.9 \pm 0.4$ as compared to $0.9 \pm 0.2$ for Akita-Saline, Timp1: $8.9 \pm 3.3$ as compared to $1.3 \pm 0.2$ for Akita-Saline, $p<0.05)$. On the other hand, Ins ${ }^{\text {Akita }}$ mice that received intravitreal injections of ASC-CM did not show any further increase in gene expression as compared to Ins2 $2^{\text {Akita }}$ mice that received saline (Ccl2: $4.3 \pm 1.0$, Ch25h: $2.3 \pm 0.4$, Gbp2: $1.1 \pm 0.1$, Icam-1: $1.2 \pm 0.2$, Lgals9: $1.1 \pm 0.2$, Timp1: $1.7 \pm 0.3$ as compared to Akita-Saline, $p>0.05)$. Considering the variation in gene expression at 3 weeks post intravitreal injection, specifically in Ins $2^{\text {Akita }}$ mice that received ASCs, retinas at day 3 post injections were also assessed for gene expression (Additional file 7: Figure S7). At day 3 post-injection, Ins $2^{\text {Akita }}$ mice experienced similarly altered expression of genes associated with retinal inflammation and neurovascular tissue remodeling in response to diabetes-related stressors compared to age-matched WT mice (Ch25h: 4.2 \pm 0.7 , Crybb2: $7.1 \pm$ 2.6, Edn2: $2.3 \pm 0.6$, Gbp2: $1.3 \pm 0.2$, Icam1: $1.4 \pm 0.2$, Lgals9: $2.3 \pm 0.4$, Lama5: $1.4 \pm 0.1$, Serping: $2.2 \pm 0.2$, Timp1: $3.2 \pm 0.7$ as compared to WT mice: $1 \pm 0.0, p<$ $0.05)$. However, Ins $2^{\text {Akita }}$ mice that received intravitreal injections of ASCs or ASC-CM did not show any further increase in the expression profile of genes, with the exception of Edn2 $(5.0 \pm 0.8$ for Akita-ASCs, $7.1 \pm 1.1$ for Akita-ASC-CM; $p<0.05)$.

\section{Discussion}

The Ins2 $2^{\text {Akita }}$ model is superior to chemically induced models of DR as it is highly reproducible, can facilitate longitudinal studies of complications, and provides a relevant genetic background for testing new therapeutic strategies for early intervention in DR [39]. Accordingly, this mouse model was used previously to demonstrate the therapeutic benefits of endothelial colony-forming cells derived from cord blood [40]. The salient findings of current study are (1) both ASCs and ASC-CM therapeutically benefit the retina and improve vision in Ins $2^{\text {Akita }}$ model of NPDR mostly through preserved neurovascular architecture, attenuated inflammation, and vascular leakage, (2) immune competent Ins $2^{\text {Akita }}$ mice lack any apparent immune rejection of ASCs, supporting their allogeneic transplantation, and (3) ASC-CM is relatively more effective than ASCs at the doses tested for early manifestations of NPDR. Our study corroborates our previous findings that ASCs are able to rescue the neural retina from hyperglycemia-induced degeneration observed in STZinduced DR model [24] thereby establishing adult stem cells and their secretome as possible regenerative therapies for NPDR.

Although the cell surface expression of platelet-derived growth factor receptor (PDGFR $\beta, \mathrm{CD} 140 \mathrm{~b}$ ) is not a bona fide ASC marker [58], it is constitutively expressed in most ASCs, regardless of passage number $[59,60]$ and increased with culture ranging from 40 to $70 \%$ [61]. Cd140b is thought to be a major cell surface marker defining pericytes [62], though the specific role of CD140b signaling in ASCs in regulating the angiogenic potential of retinal endothelial cells is still not completely understood. The pericytic ASCs are hypothesized to ameliorate the loss of pericytes and consequent vascular permeability in DR [24]. Because ASCs produce cytoprotective factors, it is also anticipated that they will also promote vascular and neurodegeneration repair in retinopathy [24]. Additional work from our lab has established a pivotal role for CD140b signaling in that ability of ASCs to modulate the angiogenic behavior of human retinal endothelial cells via direct or paracrine signals [41]. For these reasons, we tested CD140b-positive ASCs and their conditioned medium for their potential benefit in Ins $2^{\text {Akita }}$ model. Surprisingly, the CD140b-positive ASCs were not found in association with the retina by OCT analyses of live mice or by post-mortem histological analyses (Additional file 6 : Figure S6 and Additional file 8: Figure S8). It is possible that the number of cells injected into the eye is far below the detection threshold of our assays or insufficient to 
integrate into the retina. The apparent lack of homing of these ASCs is consistent with previous observations that MSCs are poorly retained and integrated into the retina $[26,63]$. While it is interesting that one single intravitreal injection of ASCs is sufficient to partially rescue visual function in the Ins $2^{\text {Akita }}$ model, the apparent superiority of ASC-CM suggests that the observed therapeutic benefits of ASCs are largely paracrine mediated rather than cell-mediated.

Here, we used ASC-CM from TNF $\alpha$, and IFN $\gamma^{-}$ stimulated ASCs. We have recently shown that cytokine priming can enhance the anti-inflammatory properties of ASCs and mitigate visual deficits observed in a blast injury model [64]. Cytokine-stimulated MSCs have been shown to express extracellular superoxide dismutase (SOD3), which can aid neuroprotection by mitigating oxidative stress [65]. We confirmed that SOD3 is upregulated in the CM of TNF $\alpha$ and IFN $\gamma$-stimulated ASCs (Fig. 2). Surprisingly, we found that mitochondrial superoxide dismutase (SOD2) is also present in the $\mathrm{CM}$ of TNF $\alpha$ and IFN $\gamma$-stimulated ASCs. These SODs may help mitigate hyperglycemia-induced oxidative stress seen in DR. TNF $\alpha$ and IL- $1 \beta$ are known to induce the expression of the anti-inflammatory protein TNF-stimulated gene 6 protein (TSG-6), which has shown therapeutic value in numerous animal models including ophthalmic diseases [66-68]. Activation and proliferation of retinal microglial cells are linked to DR pathology [69]. TSG-6 can suppress the expression of inflammatory gene transcripts in BV2 microglia activated with LPS [35]. We recently showed that TNF $\alpha$ and IFN $\gamma$ synergize for TSG-6 expression and that cytokine-stimulated ASC-CCM (cytokine-stimulated and concentrated CM from unsorted ASCs) more potently suppresses nitric oxide production by LPS stimulated BV2 cells than ASC-CCM from unstimulated cells [64]. IDO is known to be upregulated in IFN $\gamma$-stimulated MSCs and has been shown to limit $\mathrm{T}$ cell function and promote immune tolerance [70, 71]. Here, we confirmed that TSG-6 and IDO are present in the cytokine-stimulated ASC-CM.

Although SODs, TSG-6, and IDO may contribute to neuroprotection and suppression of inflammation in the retinas of Ins $2^{\text {Akita }}$ mice, we found many proteins that are differentially expressed in the CM of ASCs treated with cytokines. Using antibody arrays that can detect relative amounts of cytokines, chemokines, and angiogenic factors, we determined that TNF $\alpha$ and IFN $\gamma$ also significantly upregulated the secretion of IL-6, IL-8, CCL2, CXCL9, CCL5, CXCL10, CXCL11, CCL7, and ANGPT-1. Paradoxically, the induction of interleukins and chemokines in the $\mathrm{CM}$ of stimulated ASCs may be beneficial to promoting regeneration of neurovascular tissue because the initial robust recruitment of immune responders in the presence of other ASC produced regulatory molecules may play an important role in advancing the late stages of the immune response leading to inflammation resolution and tissue repair. It has been hypothesized that MSC co-culture and MSC extracellular vesicle-treated macrophage populations may promote resolution of inflammation via reduction of Th1 pathogenicity through Th17 conversion [72]. Others have also demonstrated that the induction of regulatory $\mathrm{T}$ cells by MSCs involves skewing monocytes toward M2-type macrophages [73, 74]. These findings indicate that MSC-secreted factors coordinate with controlled recruitment of immune regulators with influence over their phenotype and function at the site of injury while simultaneously initiating the process of tissue remodeling. Although the tissue remodeling process involving ASCs is complex and involves many mediators, there is evidence in that stimulation of ASC-CM elicits a response pattern aligned with controlled tissue remodeling. For example, ANG-1, a growth factor that stimulates the re-endothelialization of blood vessels thereby counteracting permeability and other pro-inflammatory effects, was increased with stimulation, while ANG-2 levels remain unchanged [75]. Since these paracrine factors can display pleiotropic and differential effects on immune modulation, chemoattraction, and tissue remodeling, it is not yet clear which protein alone or in combination contribute to the overall therapeutic effect of the ASC-CM. Loss and gain of function studies of specific proteins within the ASC-CM may identify the therapeutic roles and mechanisms of individual paracrine factors, though synergies between factors may also exist. Detailed studies of secretome composition and molecular mechanisms of action may allow for the development of a unique biologic that can be produced reproducibly and at a scale that can meet FDA requirements for human clinical studies.

Evidence compiled from clinical and basic research supports the view that DR constitutes a change in the retinal neurovascular unit comprised of interacting neurons, glia, and vasculature [76]. Ins $2^{\text {Akita }}$ heterozygous mice experience early features of DR including microglial activation, reduced GFAP expression in astrocytes, and an increase in GFAP expression by Muller cells $[39,55]$. In accordance with this observation, we show a significant increase in GFAP expression in Ins2 ${ }^{\mathrm{A}-}$ kita mice that was reduced by ASC-CM but not ASCs. This apparent difference between ASCs and ASC-CM was also observed in retinal gene expression changes observed in this model, specifically, genes coding for proteins involved in infection and immune responses (Gbp2; Lgals9; Ch25h) and in intracellular signal transduction pathways activated by cytokines and chemokines, such as adhesion and tissue structure (Icam-1; Lama5), inflammation (Ccl2; Edn2; CD11b), and protein degradation (Timp1). A recent study in an oxygen-induced retinopathy model demonstrated a similar increase in genes 
associated with retinal inflammation and neurovascular tissue remodeling 5 days post intravitreal injection of ASCs. Taken in the context of similar therapeutic results in the Ins $2^{\text {Akita }}$ mice, the targeted enhancement of genes regulating retinal inflammation and tissue modulation may be required to restore normal neurovascular tissue structure [77]. It is possible that the increase in some genes correlated with DR is a compensatory phenomenon by cells responding to ongoing stress with attempts at inflammation resolution and tissue regeneration. Therefore, the promotion of these genes may be an indication of a more robust wound healing response necessary for a therapeutic outcome that overcomes the deleterious effect of long-term chronic inflammation and oxidative stress. In support of this hypothesis, ASCs exposed to chronic levels of high glucose normalized high glucose challenged endothelial gene expression levels compared to those of normal glucose medium and also protected against oxidative stress [77]. In line with these results, we showed ASCs exposed to exogenous $\mathrm{TNF} \alpha$, and IFN $\gamma$ produces both inflammatory cytokines like IL-6 and anti-inflammatory TSG-6 and antioxidant SODs. Thus, a dynamic and complex repertoire of paracrine factors produced by ASCs may account their unique ability to treat a variety of pathological conditions across various tissues. Taken together, our results suggest that preconditioning of ASCs likely benefit the outcomes in DR.

Considering the variation in gene expression at 3 weeks post intravitreal injections, retinas at day 3 post-injection were also assessed for gene expression. Our data at day 3 demonstrated a significant upregulation of the genes Ch25h, Edn2, Icam1, Timp1, Lama5, Lgals9, and Serping in Ins2 ${ }^{\text {Akita }}$ mice that received saline $(p<0.05)$ with no further increase in most of these genes with both ASCs and ASC-CM (Additional file 7: Figure S7). Interestingly, crystallin B2, a family of crystallins that are known to have a role in the adaptive mechanisms taking place in the diabetic retina [78], is increased twofold in Ins $2^{\text {Akita }}$ mice that received ASC-CM. Endothelin-2, a candidate biomarker for controlled vascular modulation [79, 80], was significantly increased in Ins2 ${ }^{\text {Akita }}$ mice that received saline with a twofold further increase in mice that received ASCs and ASC-CM. However, for any given gene, the relative differences in expression between Ins $2^{\text {Akita }}$ mice that received ASCs versus ASC-CM was more profound at 3 weeks than at 3 days. We need more detailed temporal expression data and gain or loss of function studies of these genes, as well as studies of gene expression changes in this model, confirmed at the protein level, to fully address the cause or effect relationship of these gene transcripts in the Ins2 ${ }^{\text {Akita }}$ model with ASCs and ASC-CM.

Previously, it was reported that Ins $2^{\text {Akita }}$ mice develop retinal vascular permeability using the FITC-BSA tail vein injection method [39]. We have confirmed such leakage in the Ins $2^{\text {Akita }}$ model and show that both ASCs and ASC-CM can alleviate it. This study supports our previous observation that ASCs in an STZ-induced DR model suppress similar vascular leakiness [24]. Taken together with the observation that ASC-CM demonstrated a reduction in TER in vitro, our data suggest that ASC-produced paracrine factors affect the integrity of vascular endothelial cells in vivo. This observation is consistent with studies showing that MSC-derived conditioned medium or extracellular vesicles can protect against endothelial permeability [81-83].

Neural alterations of DR can be monitored in real-time via visual function tests such as ERG and OKN. Our results in this study demonstrate significant lower b-wave amplitudes and visual acuity in Ins $2^{\text {Akita }}$ mice suggesting retinal damage in this model. It is interesting to note that Ins2 ${ }^{\text {Akita }}$ mice that received ASCs and ASC-CM alleviated ERG deficits while only Ins2 ${ }^{\text {Akita }}$ mice that received ASC-CM group demonstrated improved OKN deficits. While the vision gains with ASC-CM were modest, they indicate that ASC-CM has the ability to reverse the progression of chronic NPDR and initiate the restoration of neurovascular homeostasis in the presence of continued systemic disease. Although the number of ASCs injected may not equate to the amount of ASC-CM injected into the eyes, the lack of positive response in the ASC group may suggest the persistence of disturbances of post-retinal connections downstream of an accessory optic system that has been linked to OKN defects [84]. Considering the fact that ERG deficits are associated with retinal inflammation [85], and Ins $2^{\text {Akita }}$ mice that received ASC-CM had relatively decreased retinal inflammation, it may be possible to suggest that ASC-CM may elicit its benefits by suppressing retinal neuronal inflammation.

Previously, it was established that healthy, but not diabetic, mouse-derived ASCs were protective against vascular dropout in the Akimba diabetic mouse model [86]. The same study failed to demonstrate any apparent benefit with conditioned medium derived from mouse ASCs [86]. We have similarly found a protective effect of healthy human ASCs in the Akita model and have also established a therapeutic benefit with human ASC-CM. The differences between the two studies include (1) inherent differences in the models due to different genotypes, (2) different species of ASCs were studied, (3) here neurovascular, rather than vascular, structures were studied, and (4) the ASC-CM generated in our study is from human cells primed with a cytokine cocktail that might have produced beneficial proteins at the required therapeutic dose.

Our study is a step forward in the field to suggest an allogenic ASC and cell-free ASC-CM therapy for NPDR. 
While ASC-CM appears to provide similar beneficial outcomes compared to that of ASCs but without the increased risk of the occasional mass of cells overlying the photosensitive retina, retinal hemorrhage and retinal detachments were observed in the group that received ASCs. Compared to ASCs, the use of ASC-CM is also without observable unwanted side effects, including subretinal fluid accumulation and/or retinal detachment that was observed in human subjects [33]. Although the use of ASC-CM is promising, more studies are warranted to explore the long-term safety and effectiveness of such treatment further. If ASC-CM is indeed the better therapy, then it would be pertinent to determine the best means of treating patients longitudinally. One of the benefits of ASC treatment is the presence of actual cells that allow for continued paracrine factor secretion for some time after cells are delivered to the vitreous as described in studies with ASC and other MSCs [87-91]. With ASC-CM, we would need to explore whether regular injections are a safer alternative compared to a potential depot implant of cells.

We readily acknowledge some of the limitations of this initial study. The ASCs and ASC-CM used in the Ins $2^{\text {Akita }}$ mouse experiments come from the CD140b-sorted cells from a single human donor and may, therefore, have unique or clonogenic properties. One single intravitreal injection in our studies might have produced only limited exposure to the therapeutic. Note that we used human ASCs in the mouse because these are the cells that would be tested in human clinical trials. However, suboptimal responses across species may exist if relevant human proteins or macromolecules do not efficiently interact with mouse targets. In this study, ASCs demonstrated some risk including the occasional mass of cells overlying the photosensitive retina, prolonged perturbation of neurovascular tissue remodeling gene expression, and retinal detachments. Moreover, the relative potency of ASCs versus concentrated ASC-CM is not comparable, warranting additional studies with escalating and repeated dosing. We have been able to study only $20 \times$ concentrated ASC-CM, and future studies with lower or higher concentrations may be necessary to optimize the dose response. Although ASC-CM provided beneficial outcomes on visual function and vascular leakage without other observed safety concerns in the Ins2 $2^{\text {Akita }}$ model, additional pre-clinical studies are required to establish long-term safety, tolerability, and effectiveness of such treatment. Finally, we chose to do intravitreal injections as it benefits from direct delivery of the ASCs into the eye close to the damaged retinal vasculature, in line with other cell therapies for DR. However, other routes of administration require further exploration.

\section{Conclusions}

Using a well-characterized Ins2 $2^{\text {Akita }}$ NPDR model, we demonstrated that one single intravitreal injection of ASCs and/or ASC-CM therapeutically benefit the retina by modulating the neurovascular system and improving vision. Molecular and histological studies further confirm the beneficial effects of the ASCs and ASC-CM in vivo. Future studies are needed to identify the specific proteins involved in the observed beneficial effects. Long-term studies will focus on the safety and efficacy of stem cell treatments, including the potential for rejection or the therapeutic value of reinjection, as well as any relative advantages of ASC-CM for manufacturing, quality, safety, or effectiveness of ASC-derived therapies for DR.

\section{Additional files}

Additional file 1: Figure S1. Ins $2^{\text {Akita }}$ mice had markedly higher blood glucose levels. Blood glucose concentration $(\mathrm{mg} / \mathrm{dL})$ in the study groups. Data represent mean \pm SEM from $n=3-8$ animals. ${ }^{*} p<0.05$ compared to WT mice. (TIF $103 \mathrm{~kb}$ )

Additional file 2: Figure S2. Isolation and separation of CD140bpositive ASCs by FACS sorting. Representative flow cytometric histograms of (A) unstained control (B) isotype antibody control and (C) the expression of CD140b. ASCs were labeled with CD140b-PECy5 mAb and sorted by FACS. ASCs were gated based on forward (FSC-A), and side scatter (SSC-A) area to gate the live-viable cells. Single cells from viable cell population were gated using side scatter height and width (SSC-W, SSC$H)$, forward scatter height (FSC-W, FSC-H). Further, using a histogram plot (x-axis: PEcy5 positive vs Y-axis: cell count), CD140b + ASC (right side gate) and CD140b- ASC (left side gate) were sorted. Data is from one donor with 2 other donor with similar results. (TIF $2704 \mathrm{~kb}$ )

Additional file 3: Figure S3. Cytokine priming preserves cell viability and enhances chemokine and angiogenic proteins in ASC-CM. (A) Assessment of cell viability by MTT proliferation assay did not affect cell viability before and after priming with cytokines. Data represent Mean \pm SD from one donor performed in triplicates. Differential expression of all assessed (B) chemokines and (C) angiogenic proteins in primed versus un-primed ASC-CM. (TIF $1333 \mathrm{~kb}$ )

Additional file 4: Figure S4. Ins $2^{\text {Akita }}$ mice demonstrate no apparent retinal vascular permeability with or without ASCs and ASC-CM. (A) Representative brightfield images showing no apparent architectural defects except for some Ins2Akita mice that received ASCs injection demonstrating hemorrhages (arrows). (B) Representative green fluorescence images showing no apparent vascular leakiness in any study groups. Data is representative of $n=6-8$ animals/group. (TIF $3396 \mathrm{~kb}$ )

Additional file 5: Figure S5. Ins $2^{\text {Akita }}$ mice show altered a-wave amplitudes significantly rescued with ASCs and ASC-CM. (A) a-wave amplitude measurement in mice at various flash intensities. (B). the a-wave amplitude at 25 cd.s. $\mathrm{cm}^{2}$ expressed as $\mu \mathrm{V}$. Data represents combined Mean \pm SEM from $n=12-20$ animals/group of the left eye only performed in 3 separate batches. ${ }^{*} p<0.05$ compared to WT mice. (TIF $262 \mathrm{~kb}$ )

Additional file 6: Figure S6. Ins $2^{\text {Akita }}$ mice demonstrate no apparent changes in histological and OCT defects with and without ASCs and ASCCM. (A). Representative photomicrographs of H\&E stainings from all study groups. Scale $=50 \mu \mathrm{m}$. Data represents 5-7 animals/group from one batch. (B). Representative brightfield images showing b-scan location (upper panels) with the retinal and choroidal layers (Lower panels). No apparent structural defects except for occasional hemorrhages in Ins2 $2^{\text {Akita }}$ mice that received ASCs injection noted. The central bright spot is a dust particle trapped in the camera and should be considered as an artifact. Data represents 3-4 animals/group from one batch. (TIF $11174 \mathrm{~kb}$ ) 
Additional file 7: Figure S7. Ins $2^{\text {Akita }}$ mice display differential gene expression with and without ASCs and ASC-CM. Gene transcripts associated with retinal inflammation and neurovascular tissue remodeling by TaqMan QPCR expressed as fold change normalized to internal control in the study groups 3 days post intravitreal injections. Data represented as the Mean \pm SEM from $n=6-8$ animals/group normalized to WT mice. ${ }^{*} p$ $<0.05$ compared to WT mice; \# $\mathrm{p}<0.05$ compared to Ins2 ${ }^{\text {Akita }}$ mice that received saline; $\$ p<0.05$ compared to Ins $2^{\text {Akita }}$ mice that received ASCs. (TIF 238 kb)

Additional file 8: Figure S8. Incorporation of intravitreally delivered ASCs into host vasculature in Ins $2^{\text {Akita }}$ mice as assessed by human histone lgG immunostaining. Representative confocal images demonstrated no immunostaining for human lgG (thus no association of the ASCs with host vessels or any structures within the retina) in wildtype mice (A) or Ins $2^{\text {Akita }}$ mice that received ASCs (B). Positive immunostaining is shown with human ASCs cultured in vitro (C). Retinal sections incubated with no primary antibody demonstrated immunostaining specificity of the antibody (D). Data shown are representative of 3-5 animals/group. Scale $=50 \mu \mathrm{m}$. (TIF $3769 \mathrm{~kb}$ )

\section{Acknowledgements}

Authors acknowledge the technical support from TJ Hollingsworth, Ph.D. (Neuroscience Institute, UTHSC). Authors acknowledge Lada Klaic, Ph.D. (Cell Care Therapeutics Inc), Houman David Hemmati, M.D., Ph.D. (Levation Pharma Ltd), and Jeffrey L. Edelman, Ph.D. (Ocular Drug Discovery and Development) for insightful and constructive editorial assistance and discussions.

\section{Funding}

This study was supported by grants from the National Eye Institute (EY023427), unrestricted funds from Research to Prevent Blindness to R.G. The funders played no role in the conduct of the study, collection of data, management of the study, analysis of data, interpretation of data, or preparation of the manuscript.

\section{Availability of data and materials}

All data generated and/or analyzed during this study are included in this published article. Data sharing not applicable to this article as no datasets were generated or analyzed during the current study.

\section{Authors' contributions}

SLE, WE, MP, RL, and RP contributed to the design, collection, and assembly of data, data analysis and interpretation, and manuscript writing; KJ, SA, JG, and SMT contributed to the collection and assembly of data; NS contributed to the conception and design and manuscript writing; RG contributed to the conception and design, collection and assembly of data, data analysis and interpretation, manuscript writing, and final approval of the manuscript. All authors read and approved the final manuscript.

\section{Ethics approval and consent to participate}

Studies involving human adipose tissue were approved by UTHSC Institutional Review Board in accordance with relevant guidelines and regulations following the tenets of the Declaration of Helsinki. Institutional IRB approved the study as an exempt since the study involved de-identified cell lines from commercial sources. Animal studies were approved by the Institutional Animal Care and Use Committee, University of Tennessee Health Sciences Center (UTHSC), following the guidelines as per the Association for Research in Vision and Ophthalmology (ARVO) Statement for the Use of Animals in Ophthalmic and Vision Research.

\section{Consent for publication}

Not applicable.

\section{Competing interests}

NS and RG are co-founders and hold equity in Cell Care Therapeutics Inc. whose interest is in the use of adipose-derived stromal cells in visual disorders. MP is an employee of Cell Care Therapeutics Inc. with equity. None of the other authors declare any financial conflicts.

\section{Publisher's Note}

Springer Nature remains neutral with regard to jurisdictional claims in published maps and institutional affiliations.

\section{Author details}

${ }^{1}$ Ophthalmology, University of Tennessee Health Science Center, 930 Madison Ave, Suite\#768, Memphis, TN 38163, USA. ${ }^{2}$ Anatomy and Neurobiology, University of Tennessee Health Science Center, Memphis, TN 38163, USA. ${ }^{3}$ Pharmacology \& Toxicology Department, College of Pharmacy, Mansoura University, Mansoura, Egypt. ${ }^{4}$ Cell Care Therapeutics, Inc., Monrovia, CA 91016, USA.

Received: 2 July 2018 Revised: 5 October 2018 Accepted: 23 October 2018 Published online: 21 November 2018

\section{References}

1. Klein R, Deng Y, Klein BE, Hyman L, Seddon J, Frank RN, Wallace RB, Hendrix SL, Kuppermann BD, Langer RD, Kuller L, Brunner R, Johnson KC, Thomas AM, Haan M. Cardiovascular disease, its risk factors and treatment, and agerelated macular degeneration: Women's Health Initiative Sight Exam ancillary study. Am J Ophthalmol. 2007;143(3):473-83.

2. Klein $\mathrm{R}$, Klein $\mathrm{BE}$. The prevalence of age-related eye diseases and visual impairment in aging: current estimates. Invest Ophthalmol Vis Sci. 2013; 54(14):ORSF5-ORSF13.

3. Aiello LP, Gardner TW, King GL, Blankenship G, Cavallerano JD, Ferris FL 3rd, Klein R. Diabetic retinopathy. Diabetes Care. 1998;21(1):143-56.

4. Shah CA. Diabetic retinopathy: a comprehensive review. Indian J Med Sci. 2008:62(12):500-19.

5. Kempen JH, O'Colmain BJ, Leske MC, Haffner SM, Klein R, Moss SE, Taylor HR, Hamman RF. The prevalence of diabetic retinopathy among adults in the United States. Arch Ophthalmol. 2004;122(4):552-63.

6. Klein R, Klein BE, Moss SE, Davis MD, DeMets DL. The Wisconsin epidemiologic study of diabetic retinopathy. II. Prevalence and risk of diabetic retinopathy when age at diagnosis is less than 30 years. Arch Ophthalmol. 1984;102(4):520-6.

7. Klein R, Klein BE, Moss SE, Davis MD, DeMets DL. The Wisconsin epidemiologic study of diabetic retinopathy. III. Prevalence and risk of diabetic retinopathy when age at diagnosis is 30 or more years. Arch Ophthalmol. 1984;102(4):527-32.

8. Photocoagulation for diabetic macular edema. Early Treatment Diabetic Retinopathy Study report number 1. Early Treatment Diabetic Retinopathy Study research group. Arch Ophthalmol. 1985;103(12):1796-806.

9. Preliminary report on effects of photocoagulation therapy. The Diabetic Retinopathy Study Research Group. Am J Ophthalmol. 1976;81(4):383-96.

10. Jackson TL, Nicod E, Angelis A, Grimaccia F, Pringle E, Kanavos P. Pars plana vitrectomy for diabetic macular edema: a systematic review, meta-analysis, and synthesis of safety literature. Retina. 2017;37(5):886-95.

11. Two-year course of visual acuity in severe proliferative diabetic retinopathy with conventional management. Diabetic Retinopathy Vitrectomy Study (DRVS) report \#1. Ophthalmology. 1985;92(4):492-502.

12. Arevalo JF, Garcia-Amaris RA. Intravitreal bevacizumab for diabetic retinopathy. Curr Diabetes Rev. 2009;5(1):39-46.

13. Ozkiris A. Intravitreal bevacizumab (Avastin) for primary treatment of diabetic macular oedema. Eye (Lond). 2009;23(3):616-20.

14. Velez-Montoya R, Fromow-Guerra J, Burgos O, Landers MB 3rd, MoralesCaton V, Quiroz-Mercado $\mathrm{H}$. The effect of unilateral intravitreal bevacizumab (avastin), in the treatment of diffuse bilateral diabetic macular edema: a pilot study. Retina. 2009;29(1):20-6.

15. Haritoglou C, Kook D, Neubauer A, Wolf A, Priglinger S, Strauss R, Gandorfer A, Ulbig M, Kampik A. Intravitreal bevacizumab (Avastin) therapy for persistent diffuse diabetic macular edema. Retina. 2006;26(9):999-1005.

16. Michaelides M, Kaines A, Hamilton RD, Fraser-Bell S, Rajendram R, Quhill F, Boos CJ, Xing W, Egan C, Peto T, Bunce C, Leslie RD, Hykin PG. A prospective randomized trial of intravitreal bevacizumab or laser therapy in the management of diabetic macular edema (BOLT study) 12-month data: report 2. Ophthalmology. 2010;117(6):1078-1086.e2.

17. Stewart MW, Flynn HW Jr, Schwartz SG, Scott IU. Extended duration strategies for the pharmacologic treatment of diabetic retinopathy: current status and future prospects. Expert Opin Drug Deliv. 2016;13(9):1277-87. 
18. Hattori T, Shimada H, Nakashizuka H, Mizutani Y, Mori R, Yuzawa M. Dose of intravitreal bevacizumab (Avastin) used as preoperative adjunct therapy for proliferative diabetic retinopathy. Retina. 2010;30(5):761-4.

19. Mason JO 3rd, Nixon PA, White MF. Intravitreal injection of bevacizumab (Avastin) as adjunctive treatment of proliferative diabetic retinopathy. Am J Ophthalmol. 2006;142(4):685-8.

20. Cheung N, Mitchell P, Wong TY. Diabetic retinopathy. Lancet. 2010; 376(9735):124-36.

21. Lattanzio R, Cicinelli MV, Bandello F. Intravitreal steroids in diabetic macular edema. Dev Ophthalmol. 2017:60:78-90.

22. Robinson R, Barathi VA, Chaurasia SS, Wong TY, Kern TS. Update on animal models of diabetic retinopathy: from molecular approaches to mice and higher mammals. Dis Model Mech. 2012;5(4):444-56.

23. Bhattacharya $S$, Gangaraju R, Chaum E. Recent advances in retinal stem cell therapy. Curr Mol Biol Rep. 2017;3(3):172-82

24. Rajashekhar G, Ramadan A, Abburi C, Callaghan B, Traktuev DO, EvansMolina C, Maturi R, Harris A, Kern TS, March KL. Regenerative therapeutic potential of adipose stromal cells in early stage diabetic retinopathy. PLoS One. 2014;9(1):e84671.

25. Mendel TA, Clabough EB, Kao DS, Demidova-Rice TN, Durham JT, Zotter BC, Seaman SA, Cronk SM, Rakoczy EP, Katz AJ, Herman IM, Peirce SM, Yates PA Pericytes derived from adipose-derived stem cells protect against retinal vasculopathy. PLoS One. 2013;8(5):e65691.

26. Ezquer M, Urzua CA, Montecino S, Leal K, Conget P, Ezquer F. Intravitreal administration of multipotent mesenchymal stromal cells triggers a cytoprotective microenvironment in the retina of diabetic mice. Stem Cell Res Ther. 2016;7:42.

27. Rajashekhar G. Mesenchymal stem cells: new players in retinopathy therapy. Front Endocrinol (Lausanne). 2014;5:59.

28. Frese L, Dijkman PE, Hoerstrup SP. Adipose tissue-derived stem cells in regenerative medicine. Transfus Med Hemother. 2016;43(4):268-74.

29. Traktuev DO, Merfeld-Clauss S, Li J, Kolonin M, Arap W, Pasqualini R, Johnstone BH, March KL. A population of multipotent CD34-positive adipose stromal cells share pericyte and mesenchymal surface markers, reside in a periendothelial location, and stabilize endothelial networks. Circ Res. 2008;102(1):77-85.

30. Chen CW, Okada M, Proto JD, Gao X, Sekiya N, Beckman SA, Corselli M, Crisan M, Saparov A, Tobita K, Peault B, Huard J. Human pericytes for ischemic heart repair. Stem Cells. 2013;31(2):305-16.

31. Bouacida A, Rosset P, Trichet V, Guilloton F, Espagnolle N, Cordonier T, Heymann D, Layrolle P, Sensebe L, Deschaseaux F. Pericyte-like progenitors show high immaturity and engraftment potential as compared with mesenchymal stem cells. PLoS One. 2012;7(11):e48648.

32. Saraf SS, Cunningham MA, Kuriyan AE, Read SP, Rosenfeld PJ, Flynn HW Jr, Albini TA. Bilateral retinal detachments after intravitreal injection of adiposederived 'stem cells' in a patient with exudative macular degeneration. Ophthalmic Surg Lasers Imaging Retina. 2017;48(9):772-5.

33. Kuriyan AE, Albini TA, Townsend $J H$, Rodriguez M, Pandya HK, Leonard RE 2nd, Parrott MB, Rosenfeld PJ, Flynn HW Jr, Goldberg JL. Vision loss after intravitreal injection of autologous "stem cells" for AMD. N Engl J Med. 2017:376(11):1047-53.

34. Zhang R, Liu Y, Yan K, Chen L, Chen XR, Li P, Chen FF, Jiang XD. Anti-inflammatory and immunomodulatory mechanisms of mesenchymal stem cell transplantation in experimental traumatic brain injury. J Neuroinflammation. 2013;10:106.

35. Liu $Y$, Zhang $R$, Yan $K$, Chen F, Huang W, Lv B, Sun C, Xu L, Li F, Jiang $X$. Mesenchymal stem cells inhibit lipopolysaccharide-induced inflammatory responses of BV2 microglial cells through TSG-6. J Neuroinflammation. 2014;11:135.

36. Xie J, Broxmeyer HE, Feng D, Schweitzer KS, Yi R, Cook TG, Chitteti BR, Barwinska D, Traktuev DO, Van Demark MJ, Justice MJ, Ou X, Srour EF, Prockop DJ, Petrache I, March KL. Human adipose-derived stem cells ameliorate cigarette smoke-induced murine myelosuppression via secretion of TSG-6. Stem Cells. 2015;33(2):468-78.

37. Choi H, Lee RH, Bazhanov N, Oh JY, Prockop DJ. Anti-inflammatory protein TSG-6 secreted by activated MSCs attenuates zymosan-induced mouse peritonitis by decreasing TLR2/NF-kappaB signaling in resident macrophages. Blood. 2011;118(2):330-8.

38. Harting MT, Srivastava AK, Zhaorigetu S, Bair H, Prabhakara KS, Toledano Furman NE, Vykoukal JV, Ruppert KA, Cox CS Jr, Olson SD. Inflammationstimulated mesenchymal stromal cell-derived extracellular vesicles attenuate inflammation. Stem Cells. 2018;36(1):79-90.
39. Barber AJ, Antonetti DA, Kern TS, Reiter CE, Soans RS, Krady JK, Levison SW, Gardner TW, Bronson SK. The Ins2Akita mouse as a model of early retinal complications in diabetes. Invest Ophthalmol Vis Sci. 2005;46(6):2210-8.

40. Cahoon JM, Rai RR, Carroll LS, Uehara H, Zhang X, O'Neil CL, Medina RJ, Das SK, Muddana SK, Olson PR, Nielson S, Walker K, Flood MM, Messenger WB, Archer BJ, Barabas P, Krizaj D, Gibson CC, Li DY, Koh GY, Gao G, Stitt AW, Ambati BK. Intravitreal AAV2.COMP-Ang1 prevents neurovascular degeneration in a murine model of diabetic retinopathy. Diabetes. 2015;64(12):4247-59.

41. Periasamy R, Elshaer SL, Gangaraju R. CD140b (PDGFRß) signaling in adiposederived stem cells mediates angiogenic behavior of retinal endothelial cells. Regen Eng Transl Med. 2018; In Press (https://rdcu.be/2caQ).

42. Rajashekhar G, Shivanna M, Kompella UB, Wang Y, Srinivas SP. Role of MMP9 in the breakdown of barrier integrity of the corneal endothelium in response to TNF-alpha. Exp Eye Res. 2014;122:77-85.

43. Prusky GT, Alam NM, Beekman S, Douglas RM. Rapid quantification of adult and developing mouse spatial vision using a virtual optomotor system. Invest Ophthalmol Vis Sci. 2004;45(12):4611-6.

44. Lenin R, Nagy PG, Alli S, Rao VR, Clauss MA, Kompella UB, Gangaraju R. Critical role of endoplasmic reticulum stress in chronic endothelial activation-induced visual deficits in tie2-tumor necrosis factor mice. J Cell Biochem. 2018;119(10):8460-71.

45. Walshe TE, Saint-Geniez M, Maharaj AS, Sekiyama E, Maldonado AE, D'Amore PA. TGF-beta is required for vascular barrier function, endothelial survival and homeostasis of the adult microvasculature. PLoS One. 2009;4(4):e5149.

46. Corson TW, Samuels BC, Wenzel AA, Geary AJ, Riley AA, McCarthy BP, Hanenberg H, Bailey BJ, Rogers PI, Pollok KE, Rajashekhar G, Territo PR. Multimodality imaging methods for assessing retinoblastoma orthotopic xenograft growth and development. PLoS One. 2014;9(6):e99036.

47. Li Q, Verma A, Han PY, Nakagawa T, Johnson RJ, Grant MB, Campbell-Thompson M, Jarajapu YP, Lei B, Hauswirth WW. Diabetic eNOS-knockout mice develop accelerated retinopathy. Invest Ophthalmol Vis Sci. 2010;51(10):5240-6.

48. Cai J, Wu L, Qi X, Li Calzi S, Caballero S, Shaw L, Ruan Q, Grant MB, Boulton ME. PEDF regulates vascular permeability by a gamma-secretase-mediated pathway. PLoS One. 2011;6(6):e21164

49. Zhang $Q$, Zhang ZM. Oxygen-induced retinopathy in mice with retinal photoreceptor cell degeneration. Life Sci. 2014;102(1):28-35.

50. Rajashekhar G, Loganath A, Roy AC, Chong SS, Wong YC. Hypoxia upregulated angiogenin and down-regulated vascular cell adhesion molecule1 expression and secretion in human placental trophoblasts. J Soc Gynecol Investig. 2005;12(5):310-9.

51. Zhang Q, Jiang Y, Toutounchian JJ, Soderland C, Yates CR, Steinle JJ. Insulinlike growth factor binding protein-3 inhibits monocyte adhesion to retinal endothelial cells in high glucose conditions. Mol Vis. 2013;19:796-803.

52. Busik JV, Mohr S, Grant MB. Hyperglycemia-induced reactive oxygen species toxicity to endothelial cells is dependent on paracrine mediators. Diabetes. 2008;57(7):1952-65

53. Costa GN, Vindeirinho J, Cavadas C, Ambrosio AF, Santos PF. Contribution of TNF receptor 1 to retinal neural cell death induced by elevated glucose. Mol Cell Neurosci. 2012;50(1):113-23.

54. Hombrebueno JR, Chen M, Penalva RG, Xu H. Loss of synaptic connectivity, particularly in second order neurons is a key feature of diabetic retinal neuropathy in the Ins2Akita mouse. PLoS One. 2014;9(5):e97970.

55. McLenachan S, Chen X, McMenamin PG, Rakoczy EP. Absence of clinical correlates of diabetic retinopathy in the Ins2Akita retina. Clin Exp Ophthalmol. 2013;41(6):582-92.

56. landiev I, Biedermann B, Bringmann A, Reichel MB, Reichenbach A, Pannicke T. Atypical gliosis in Muller cells of the slowly degenerating RDS mutant mouse retina. Exp Eye Res. 2006;82(3):449-57.

57. Freeman WM, Bixler GV, Brucklacher RM, Walsh E, Kimball SR, Jefferson LS, Bronson SK. Transcriptomic comparison of the retina in two mouse models of diabetes. J Ocul Biol Dis Inform. 2009:2(4):202-13.

58. Bourin P, Bunnell BA, Casteilla L, Dominici M, Katz AJ, March KL, Redl H, Rubin JP, Yoshimura K, Gimble JM. Stromal cells from the adipose tissuederived stromal vascular fraction and culture expanded adipose tissuederived stromal/stem cells: a joint statement of the International Federation for Adipose Therapeutics and Science (IFATS) and the International Society for Cellular Therapy (ISCT). Cytotherapy. 2013;15(6):641-8.

59. Ryu YJ, Cho TJ, Lee DS, Choi JY, Cho J. Phenotypic characterization and in vivo localization of human adipose-derived mesenchymal stem cells. Mol Cell. 2013;35(6):557-64. 
60. Baek SJ, Kang SK, Ra JC. In vitro migration capacity of human adipose tissue-derived mesenchymal stem cells reflects their expression of receptors for chemokines and growth factors. Exp Mol Med. 2011;43(10):596-603.

61. Maumus M, Peyrafitte JA, D'Angelo R, Fournier-Wirth C, Bouloumie A, Casteilla L, Sengenes C, Bourin P. Native human adipose stromal cells: localization, morphology and phenotype. Int J Obes. 2011;35(9):1141-53.

62. Crisan M, Corselli M, Chen WC, Peault B. Perivascular cells for regenerative medicine. J Cell Mol Med. 2012;16(12):2851-60.

63. Johnson TV, Bull ND, Hunt DP, Marina N, Tomarev SI, Martin KR Neuroprotective effects of intravitreal mesenchymal stem cell transplantation in experimental glaucoma. Invest Ophthalmol Vis Sci. 2010; 51(4):2051-9.

64. Jha KA, Pentecost M, Lenin R, Klaic L, Elshaer SL, Gentry J, Russell JM, Beland A, Reiner A, Jotterand V, Sohl N, Gangaraju R. Concentrated conditioned media from adipose tissue derived mesenchymal stem cells mitigates visual deficits and retinal inflammation following mild traumatic brain injury. Int J Mol Sci. 2018;19(7):E2016.

65. Kemp K, Gray E, Mallam E, Scolding N, Wilkins A. Inflammatory cytokine induced regulation of superoxide dismutase 3 expression by human mesenchymal stem cells. Stem Cell Rev. 2010;6(4):548-59.

66. Prockop DJ. Inflammation, fibrosis, and modulation of the process by mesenchymal stem/stromal cells. Matrix Biol. 2016;51:7-13.

67. Kim SJ, Lee HJ, Yun JH, Ko JH, Choi DY, Oh JY. Intravitreal TSG-6 suppresses laser-induced choroidal neovascularization by inhibiting CCR2+ monocyte recruitment. Sci Rep. 2015:5:11872.

68. Tuo J, Cao X, Shen D, Wang Y, Zhang J, Oh JY, Prockop DJ, Chan CC. Antiinflammatory recombinant TSG-6 stabilizes the progression of focal retinal degeneration in a murine model. J Neuroinflammation. 2012;9:59.

69. Altmann C, Schmidt MHH. The role of microglia in diabetic retinopathy: inflammation, microvasculature defects and neurodegeneration. Int J Mol Sci. 2018;19(1):110

70. Chinnadurai R, Rajan D, Qayed M, Arafat D, Garcia M, Liu Y, Kugathasan S, Anderson LJ, Gibson G, Galipeau J. Potency analysis of mesenchymal stromal cells using a combinatorial assay matrix approach. Cell Rep. 2018; 22(9):2504-17

71. Kim DS, Jang IK, Lee MW, Ko YJ, Lee D-H, Lee JW, Sung KW, Koo HH, Yoo $\mathrm{KH}$. Enhanced immunosuppressive properties of human mesenchymal stem cells primed by interferon- $\gamma$. EBioMedicine. 2018;28:261-73.

72. Hyvärinen K, Holopainen M, Skirdenko V, Ruhanen H, Lehenkari $P$, Korhonen $M$, Käkelä R, Laitinen $S$, Kerkelä E. Mesenchymal stromal cells and their extracellular vesicles enhance the anti-inflammatory phenotype of regulatory macrophages by downregulating the production of interleukin (IL)-23 and IL-22. Front Immunol. 2018;9:771.

73. Chiossone L, Conte R, Spaggiari GM, Serra M, Romei C, Bellora F, Becchetti F, Andaloro A, Moretta L, Bottino C. Mesenchymal stromal cells induce peculiar alternatively activated macrophages capable of dampening both innate and adaptive immune responses. Stem Cells. 2016;34(7):1909-21.

74. Melief SM, Schrama E, Brugman MH, Tiemessen MM, Hoogduijn MJ, Fibbe WE, Roelofs H. Multipotent stromal cells induce human regulatory T cells through a novel pathway involving skewing of monocytes toward antiinflammatory macrophages. Stem Cells. 2013;31(9):1980-91.

75. Takahashi M, Suzuki E, Kumano S, Oba S, Sato T, Nishimatsu H, Kimura K, Nagano T, Hirata Y. Angiopoietin-1 mediates adipose tissue-derived stem cell-induced inhibition of neointimal formation in rat femoral artery. Circ $\mathrm{J}$. 2013;77(6):1574-84.

76. Antonetti DA, Klein R, Gardner TW. Diabetic retinopathy. N Engl J Med. 2012;366(13):1227-39.

77. Hajmousa G, Przybyt E, Pfister F, Paredes-Juarez GA, Moganti K, Busch S, Kuipers J, Klaassen I, van Luyn MJA, Krenning G, Hammes HP, Harmsen MC. Human adipose tissue-derived stromal cells act as functional pericytes in mice and suppress high-glucose-induced proinflammatory activation of bovine retinal endothelial cells. Diabetologia. 2018;61(11):2371-85.

78. Heise EA, Marozas LM, Grafton SA, Green KM, Kirwin SJ, Fort PE. Strainindependent increases of crystallin proteins in the retina of type 1 diabetic rats. PLoS One. 2013:8(12):e82520.

79. Binz N, Rakoczy EP, Ali Rahman IS, Vagaja NN, Lai CM. Biomarkers for diabetic retinopathy - could endothelin 2 be part of the answer? PLoS One. 2016;11(8):e0160442.
80. Rattner A, Yu H, Williams J, Smallwood PM, Nathans J. Endothelin-2 signaling in the neural retina promotes the endothelial tip cell state and inhibits angiogenesis. Proc Natl Acad Sci U S A. 2013;110(40):E3830-9.

81. Potter DR, Miyazawa BY, Gibb SL, Deng X, Togaratti PP, Croze RH, Srivastava AK, Trivedi A, Matthay M, Holcomb JB, Schreiber MA, Pati S. Mesenchymal stem cell-derived extracellular vesicles attenuate pulmonary vascular permeability and lung injury induced by hemorrhagic shock and trauma. J Trauma Acute Care Surg. 2018;84(2):245-56.

82. Yang Y, Chen QH, Liu AR, Xu XP, Han JB, Qiu HB. Synergism of MSCsecreted HGF and VEGF in stabilising endothelial barrier function upon lipopolysaccharide stimulation via the Rac1 pathway. Stem Cell Res Ther. 2015;6:250.

83. Lu H, Poirier C, Cook T, Traktuev DO, Merfeld-Clauss S, Lease B, Petrache I, March KL, Bogatcheva NV. Conditioned media from adipose stromal cells limit lipopolysaccharide-induced lung injury, endothelial hyperpermeability and apoptosis. J Transl Med. 2015;13:67.

84. Aung MH, Kim MK, Olson DE, Thule PM, Pardue MT. Early visual deficits in streptozotocin-induced diabetic long evans rats. Invest Ophthalmol Vis Sci. 2013;54(2):1370-7

85. Yeh P-T, Huang H-W, Yang C-M, Yang W-S, Yang C-H. Astaxanthin inhibits expression of retinal oxidative stress and inflammatory mediators in Streptozotocin-induced diabetic rats. PLoS One. 2016:11(1):e0146438.

86. Cronk SM, Kelly-Goss MR, Ray HC, Mendel TA, Hoehn KL, Bruce AC, Dey BK, Guendel AM, Tavakol DN, Herman IM, Peirce SM, Yates PA. Adipose-derived stem cells from diabetic mice show impaired vascular stabilization in a murine model of diabetic retinopathy. Stem Cells Transl Med. 2015:4(5):459-67.

87. Mead B, Tomarev S. Bone marrow-derived mesenchymal stem cells-derived exosomes promote survival of retinal ganglion cells through miRNAdependent mechanisms. Stem Cells Transl Med. 2017;6(4):1273-85.

88. Mead B, Logan A, Berry M, Leadbeater W, Scheven BA. Paracrine-mediated neuroprotection and neuritogenesis of axotomised retinal ganglion cells by human dental pulp stem cells: comparison with human bone marrow and adipose-derived mesenchymal stem cells. PLoS One. 2014;9(10):e109305.

89. Mead B, Hill LJ, Blanch RJ, Ward K, Logan A, Berry M, Leadbeater W, Scheven BA. Mesenchymal stromal cell-mediated neuroprotection and functiona preservation of retinal ganglion cells in a rodent model of glaucoma. Cytotherapy. 2016;18(4):487-96.

90. Nakagami H, Maeda K, Morishita R, Iguchi S, Nishikawa T, Takami Y, Kikuchi Y, Saito Y, Tamai K, Ogihara T, Kaneda Y. Novel autologous cell therapy in ischemic limb disease through growth factor secretion by cultured adipose tissue-derived stromal cells. Arterioscler Thromb Vasc Biol. 2005;25(12):2542-7.

91. Cho YJ, Song HS, Bhang S, Lee S, Kang BG, Lee JC, An J, Cha Cl, Nam DH, Kim BS, Joo KM. Therapeutic effects of human adipose stem cellconditioned medium on stroke. J Neurosci Res. 2012;90(9):1794-802.

Ready to submit your research? Choose BMC and benefit from:

- fast, convenient online submission

- thorough peer review by experienced researchers in your field

- rapid publication on acceptance

- support for research data, including large and complex data types

- gold Open Access which fosters wider collaboration and increased citations

- maximum visibility for your research: over $100 \mathrm{M}$ website views per year

At $\mathrm{BMC}$, research is always in progress.

Learn more biomedcentral.com/submissions 